\title{
THE DISTRIBUTION OF GAMMARUS SPECIES IN ESTUARIES. PART I
}

\author{
By G. M. Spooner, M.A. \\ Zoologist at the Plymouth Laboratory
}

(Text-figs. I-7)

Editor's note. This paper and that by Dr S. G. Segerstråle (this fournal pp. 219-44), independently bringing forward certain new ideas on the taxonomy of Gammarus zaddachi and $G$, locusta, were received for publication simultaneously. As this paper is a report of work largely carried out before the war, of which summarized results have already been referred to in print (e.g. Report of Council in this fournal, Vol. xxiv, pp. 444, 69I; Huxley, The Modern Synthesis, p. 315), it is given precedence. The authors have since consulted each other over matters in which their contributions overlap, in particular over the taxonomic status of the new forms they distinguish and regarding the names to be applied to them. Dr Segerstråle has kindly consented to adopt the two new names introduced by $\mathrm{Mr}$ Spooner. In this paper, where appropriate, footnotes giving cross-references to Segerstråle's paper have been inserted.

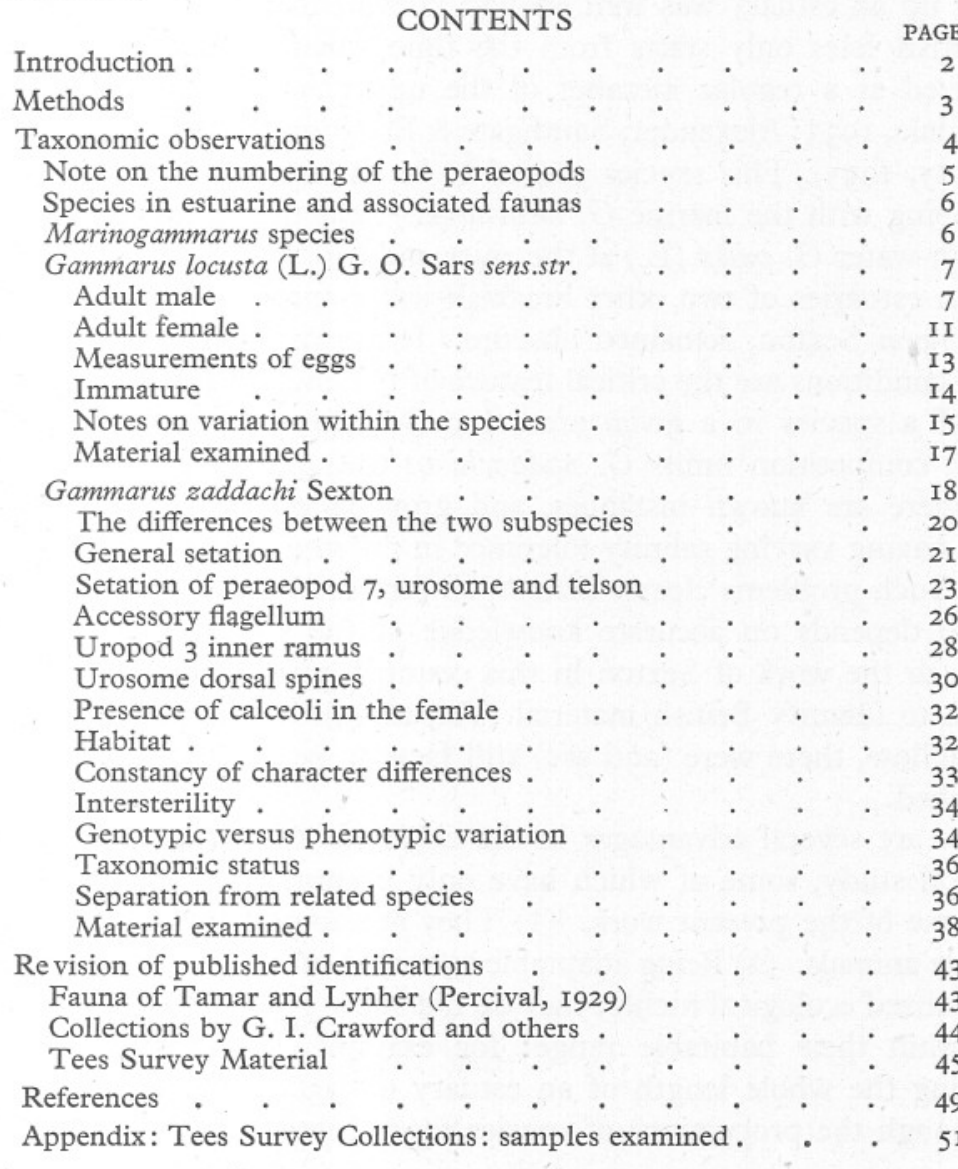




\section{INTRODUCTION}

The work of which an account is here given was largely carried out from the autumn of 1937 to the spring of 1940, when it was interrupted by the war. In taking it up again (in July I945) while facilities for field work are still limited, the author feels it useful to publish results as they stand and indicate where further work is considered advisable.

In examinations of the free-swimming bottom fauna of the Tamar and other estuaries, attention was inevitably drawn to the populations of Gammarus species, which make up the greater bulk of it. Before quantitative observations were planned, some interesting points came to light with regard to the qualitative composition of populations. This aspect lent itself more readily to study and, though by no means a new field for exploration, soon proved worth examining in greater detail than previous workers had attempted.

The broad fact of a replacement of one Gammarus species by another in passing up an estuary was well enough known, though exact knowledge for the British Isles only starts from the time when $G$. zaddachi Sexton was recognized as a regular member of the upper estuarine fauna of the Tay (Bassindale, I933; Alexander, Southgate \& Bassindale, I935) and of the Deben (Serventy, I935). This species proved to be the main brackish-water species overlapping with the marine $G$. locusta (L.) near the seaward end, and with the fresh-water G. pulex (L.) at the river end (or 'head') of the estuary. The status in estuaries of two other brackish-water species, G. duebeni Lillj. and $G$. cherreuxi Sexton, remained obscure. It has usually been suspected that salinity conditions are the critical feature of the environment which limits the range of a species in a given area; but Serventy suggested that exclusion through competition limits $G$. zaddachi to the middle reaches of estuaries, while there are known instances, and growing evidence of others, of one species having varying salinity tolerance in different parts of its geographical range. Such problems clearly demanded further study.

Much depends on accurate knowledge of the systematics of the genus. Thanks to the work of Sexton in this country, workers are now in a strong position to identify British material. Yet, as will become clear in the pages which follow, there were (and are) still facts to be added, and confusions to be rectified.

There are several advantages in the choice of Gammarus as a subject for ecological study, some of which have only become fully appreciated during the course of the present work. (I) They are among the more abundant of estuarine animals. (2) Being adaptable to varied surroundings and not limited to specialized ecological niches, they do not show gross patchiness of distribution within their habitable range: for example, a continuous population occupying the whole length of an estuary or lagoon can usually be found, even though the proportions of species represented change from one end to 
the other. (3) Furthermore, it can be said that they are indifferent to the nature of the substratum to a remarkable degree. Provided there is some kind of object which can provide them with cover or shelter, it matters not whether the bottom is muddy or stony, the water turbid or clear. Almost any kind of organic matter provides detritus on which they can feed. This means that, in so far as inanimate environmental factors limit distribution, affect growth rate, or produce any difference between two populations, these are mainly to be sought amongst the more elementary properties of the environment, such as temperature, salinity, and oxygen concentration. (4) The brackish-water species, at least, can be reared in the laboratory and subjected to controlled experimental conditions.

\section{METHODS}

The use of a box sieve makes collecting a simple matter, and overcomes the difficulty of samples getting fouled with mud. The sieve actually used is similar to that designed for handling mud samples, as described by Spooner \& Moore (1940). It forms a cube of I ft. each way, the bottom made of perforated zinc, the sides of wood, and the top open. A window of perforated zinc in one of the sides facilitates outflow of water. Suitable handles are fitted on each side at the top.

In estuaries, clumps of weed or any other suitable objects, collected from the ground in the intertidal zone or from the bed of the river channel, are placed in the sieve and well shaken in water, the sieve held three-quarters submersed. The larger objects and fragments are shaken out and discarded in turn. The macrofauna which had been contained in them accumulates at the bottom of the sieve with a mass of small fragments and debris. This is well washed by lifting the sieve in and out of the water, and transferred as desired to collecting jars. It is easy to perform these operations without injuring the animals, though care must be taken when gravel or small stones accumulate in the debris. When working in ditches or pools it is often useful to make the collections of weeds, etc., in a strong fine-meshed net, but the net contents should always be sieved, as this is the only effective method of removing mud and of concentrating the catch.

A final washing of the samples may be necessary on return to the laboratory, so that when they are placed in bowls (in appropriate mixtures of sea and fresh water) the contents are free from turbidity. Normally gammarids will comprise the greater bulk of the catch. Animals are killed by addition of strong formalin solution, and preserved in $5 \%$ neutral formalin in sea water. Samples were always examined as soon after killing as possible, while the normal colours remained unimpaired.

Examining live, or freshly killed, specimens enormously facilitates rapid diagnosis. Sometimes colour characters, lost after preservation, are valuable taxonomically - the most spectacular example, perhaps, being the orange pigment spots in G. locusta immature (see p. I4). In other respects, also, 
characters seem more easily assessed in fresh specimens, while the tissues still retain their transparency. It is clear that if amphipodists generally were able to concentrate more on fresh material, some of the existing taxonomic difficulties and confusions might never have arisen.

As a preservative, formalin is far superior to alcohol, in which specimens often become very opaque, hard and brittle. The formalin should, however, not be dissolved in water of much lower osmotic concentration than that of the body fluids; otherwise, swelling of soft tissues is apt to occur. A solution of $5 \%$ formalin in sea water is perfectly suitable for marine and brackish-water organisms, and, as far as I have tested it, for fresh-water Crustacea as well. Specimens so preserved can always without harm be placed temporarily in tap water for examination.

Microscope mounts of limbs, etc., are conveniently made in a chloral medium, e.g. Faure's Solution, as used by entomologists. No preparation is necessary; the chitin is cleared of soft matter in a short time; the medium hardens sufficiently to make ringing the mount optional; and the preparations normally keep indefinitely. Also if at any time remounting is considered desirable, the mount is simply dissolved in water. Slides intended for more temporary use can be mounted as rapidly as in water, with the advantage that they do not dry up and can be kept permanently if subsequently desired.

Apart from collections made personally, various material collected by other zoologists has been examined, and I am particularly indebted to Mrs E. W. Sexton, Mr G. I. Crawford, the late Dr K. Stephensen (Copenhagen), Prof. A. D. Hobson, Dr L. C. Beadle, Mr R. Bassindale, Mr R. Elmhirst, and Mr H.P. Moon, for the loan or presentation of material. It is a pleasure to record my thanks to Mrs Sexton for her constant interest and for the ready loan of her specimens and literature. Mr G. I. Crawford has sent me material from the British Museum, including samples collected by himself after leaving Plymouth; his earlier collections (see Crawford, 1936, 1937) were available for examination at the Plymouth Laboratory. Mr R. Bassindale's interesting series of samples from the Severn Estuary has already been recorded and commented on in the 'Studies on the Biology of the Bristol Channel' publications (Bassindale, I94I, I942 $a$, I942 $b$, I943). Prof. Hobson's material included collections from the Inner Hebrides, from streams flowing on to the shore, of which an account is published by Beadle \& Cragg (I940).

I wish further to thank Dr Sven Segerstråle for his most helpful cooperation before our respective papers were finally printed.

\section{TAXONOMIC OBSERVATIONS}

It was not possible to proceed far with ecological observations without first going rather thoroughly into the taxonomic aspects of the species under consideration. The chief reasons for this were as follows. 
(I) Species of Gammarus tend to differ in a number of minor characters in addition to any major differences which may exist. These were repeatedly examined, not only to obtain knowledge of their constancy or variability, but for the more immediate purpose of detecting atypical populations. Sometimes differences, though small, prove remarkably constant and reliable, and are invaluable when specimens are atypical, for some reason or other, in important respects (for example, as a result of stunted growth, inhibited maturity, or regenerating limbs), or with parts missing as a result of damage. It is needless to emphasize that the larger the number of characters available, the stronger is the position of the investigator.

(2) It was very desirable to determine reliably, not merely adult males, for which alone, as a rule, detailed descriptions are available, but individuals of both sexes at all ages. This aspect had to be given special attention, and some original observations are reported below. It was gratifying to find that reasonable characters exist to separate the immature of all species which are liable to occur together in Britain, even down to the smallest growth stages of which account has been taken. The necessity for dealing with specimens of all sizes also demanded closer recognition of the changes which take place during the course of life, particularly during the late immature and early maturity stages. Characters of animals whose development is gradual and whose growth continues throughout life are profitably studied in their fourdimensional aspect.

(3) Even with adult males of British species it was soon apparent that some existing descriptions were still not complete, and that the true value of some diagnostic characters had still to be adequately assessed. It was also possible to separate G. zaddachi into two readily identifiable subspecies, which, in addition to their morphological differences, have very different salinity optima.

(4) Most character-differences are comparative. It was intended at least to make a start in expressing some of them more precisely in numerical and statistical terms.

\section{Note on the numbering of the peraeopods}

It is necessary to emphasize that one change in descriptive terms has been adopted. Sexton (e.g. I9I2, I942) and Sexton \& Spooner (I940) still follow Sars (1895) and Stebbing (I906) in numbering the peraeopods from peraeon segment 3 onwards, so that the limb of segment 3 is peraeopod I and of segment 7 is peraeopod 5. Hoping that this confusing habit will soon be abandoned altogether, I propose to follow the more logical and (by now) more general practice of giving the limbs the same number as the segment (as in Chevreux \& Fage, I925). Thus the gnathopods, which are the limbs of peraeon segments I and 2, are the modified peraeopods I and 2; the first unmodified limb, or 'leg', is peraeopod 3; and the hindmost limb, that of peraeon segment 7 , is peraeopod 7. The term 'peraeopod' 
simply means the limb of a peraeon segment and has no functional implication, whereas the terms 'gnathopod' and 'leg' are functional and denote special forms of peraeopod. It is unfortunate that authorities like Sars and Stebbing have used the terms 'leg' and 'peraeopod' in exactly the reverse sense.

\section{Species in estuarine and associated faunas}

The following species have occurred in faunas examined in this work:

Marinogammarus marinus (Leach, I815).

M. obtusatus (Dahl, 1938):

M. finmarchicus (Dahl, 1938).

M. stoerensis (Reid, 1938).

Gammarus locusta (L. 1758) G. O. Sars, I895, sens.str.

G. zaddachi Sexton, 1912, typical subspecies, as here designated.

G. zaddachi salinus, subsp.nov.

G. chevreuxi Sexton, I9I3.

G. duebeni Lilljeborg, I85I.

G. (Rivulogammarus) pulex (L. 1758).

\section{Marinogammarus species}

The taxonomy of these essentially marine littoral forms has already been dealt with (Sexton \& Spooner, I940). At the same time a list of the material examined up to the summer of 1940 was included. Stephensen (1940) also gives descriptions and locality records, especially from Norway. Certain additional British material has since been examined; for example, collections made in 1942 and 1943 on the shore near the Millport Laboratory, where five of the species occurred (see Scottish Marine Biological Association, Annual Report, 1942-3, pp. IO-II).

In estuaries M. marinus alone has been encountered in abundance, extending well into the mid-estuarine reaches. It is, however, much concentrated near high-water levels, and does not enter into the low-water and mid-channel populations to which main attention is subsequently given. More will be said later, from an ecological aspect, about the upward limit of penetration into estuaries, a point which is fairly easily determined by inspection in the field.

M. olivii (M.-Edw.), of which a description was included in our 1940 paper, had not at that time been recorded from Britain. Almost simultaneously, however, Reid (1940) reported it from the River Avon in South Hants, where, at Keyhaven, it was living in water which was fresh to slightly brackish (see also Goodhart, I94I). This species, however, is not a widely spread inhabitant of estuaries and is probably extremely local. 


\section{Gammarus locusta (L.) G. O. Sars, sens.str.}

This abundant marine species has been well enough recognized from descriptions in standard works (e.g. Sars, I895; Della Valle, I893; Stebbing, I906; Chevreux \& Fage, I925) so long as purely marine faunas were under examination. In the seas of western Europe there seems to be no species with which it is liable to be confused. But in estuarine and brackish faunas it has been much confused with G. zaddachi salinus (pp. 20-I). Existing descriptions are still in need of amplifying to emphasize certain characters which have proved important in distinguishing typical locusta from other known species, and to indicate more clearly what variation occurs amongst genuine locusta populations.

It is necessary to emphasize that this account applies only to the locusta of the temperate eastern Atlantic and the North Sea (and apparently also to the western Mediterranean). I have recently been able to satisfy myself that the form occurring in northern waters (west Norway, Iceland, Greenland, Newfoundland and Arctic coasts) differs in so many respects that it is quite separable. ${ }^{1}$ It is possible also that the form of the species which inhabits the western Baltic in much lower salinities than are tolerated, for example, in Britain, may genuinely be less easily separated from $G$. zaddachi in that area. ${ }^{2}$ A fuller treatment of the characters of $G$. locusta in its whole range is deferred for a later occasion. The description here, however, is valid for the form which seems to be generally accepted as the type of locusta, following the drawings by Sars (though his description by itself is not critical enough).

\section{Adult male}

In addition to the descriptions in standard works, Sexton (I942, pp. 600-I, pl. iii, figs. 19-24) gives a list of characters useful for comparison with related species, as well as new drawings of the head, antennae and gnathopods. Only certain comments need be made. In antenna I the long accessory flagellum is a valuable diagnostic character, especially if consideration is given to the allometric changes which occur during growth. At the onset of maturity it has 7 or 8 segments which increase to $I_{3}$ or $I_{4}$ in the largest and oldest individuals. At the start it is about $\mathrm{I} \frac{1}{2}$ times the length of peduncle segment 2 , but it soon attains twice the length of that segment, and in the end is about $2 \frac{1}{3}$ times as long. As compared with $G$. zaddachi salinus, young males have about 2 segments more, the oldest about 5. In antenna I peduncle the length ratio of $3: 2:$ I for the first three segments is always closely approached. ${ }^{3}$ In

1 In essential respects these northern animals seemed much closer to zaddachi. Segerstråle (pp. 223 et seq.) has independently shown that they are to be included under that species. The description of zaddachi has only to be modified in minor respects to include this form, whereas that of locusta would need to be drastically revised.

2 But see comment on p. I8.

3 Precise micrometer measurements give ratios of 142-153:100:45-49 for the three segments, segment 3 being consistently rather less than half segment 2 . 
other species segment I is always less than the combined length of the other two, and the 3rd is often longer than half the 2nd. Gnathopod hands. Once the fully mature adult stage has been reached, the form and arrangement of the palmar spines of both gnathopods are diagnostic and easily recognized. This character should, as always, be given primary weight in critical determinations. The gnathopods are well figured for the first time by Sexton (1942, pl. iii). (N.B. Sars's drawing, I895, pl. 176, fig. I $\mathrm{p}^{2} \widehat{\alpha}$, is inaccurate, and was probably taken from a specimen of the northern form.) Gnathopod 2 hand. The exact shape of this segment is somewhat variable, though it is normally in some sense longer or narrower than in zaddachi and

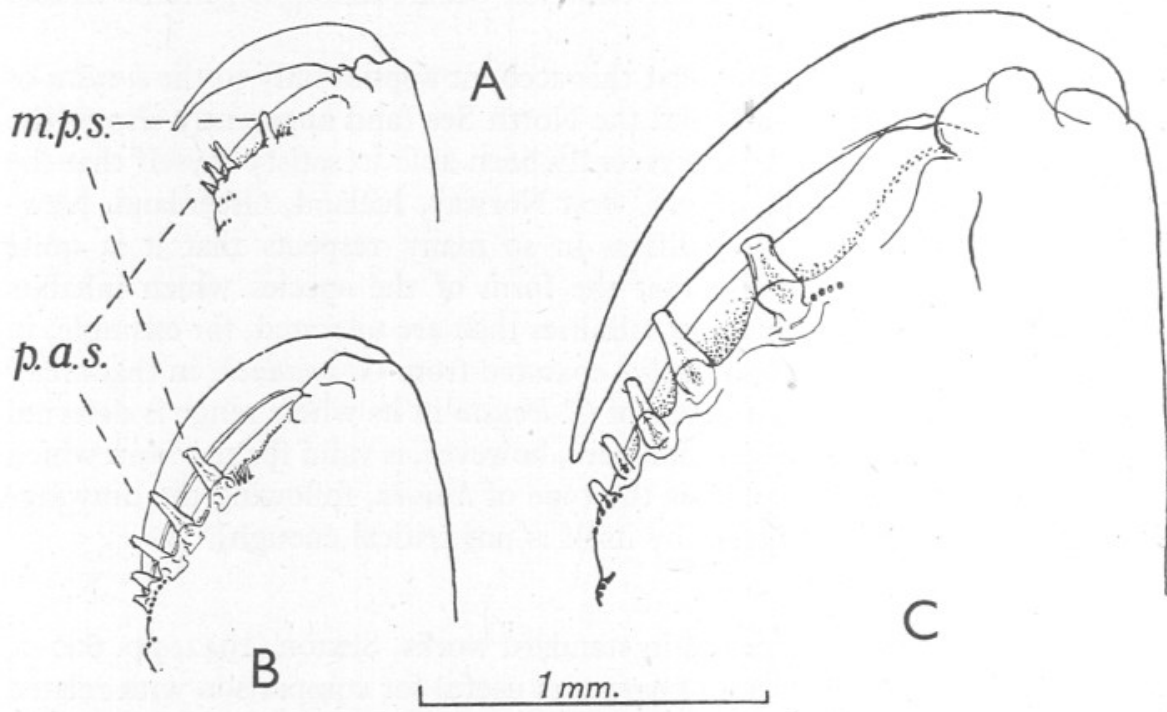

Fig. I. Gammarus locusta sens.str., male gnathopod 2 hand, distal part, with hairs omitted, to show the arrangement of the palmar spines. A, young mature male, Saltash, River Tamar, 5. iv. 38, showing the median palmar spine (m.p.s.) still separated from the palmar angle spines (p.a.s.). B, larger and fully mature male from same sample. C, large male, $25 \mathrm{~mm}$., Plymouth Sound, I2. xi. 06. In B and C all the spines tend to form a continuous row with graded intervals.

duebeni. While both the dorsal border and the palm are relatively long, the ventral border is less so; thus the palm tends to approach the length of the ventral border, especially in larger and older animals. The ventral border may diverge somewhat in an apical direction, or at least remain straight and parallel with the dorsal border: only infrequently is it rounded towards the palmar angle in a manner typically found in zaddachi. More significant is the arrangement of the palmar spines (Fig. I). The median palmar spine is succeeded, towards the palmar angle, by a regular series of spines graded in respect to size and distance between successive spines. This arrangement contrasts with a condition more frequently met in Gammarus species (including G. zaddachi, 
and the earliest mature stages of locusta itself, Fig. I A), where an isolated median spine is separated by a marked gap from a cluster of spines arising quite close together at the palmar angle. Only G. duebeni (p. 37) shows a graded series at all comparable. It is important to appreciate that the true locusta pattern is not finally attained until two or three growth stages after maturity have been reached. Another important characteristic of mature locusta hands is seen in the truncate tip and bulbous base of the median palmar spines, and of the larger of the angle spines, which thus become almost 'flaskshaped' (those of duebeni retain their original simple shape). Peraeopods 6 and 7 (examples of Pp. 7 in Fig. 2): in these limbs the more apical segments are often provided with some long, stiff, outstanding setae, arising singly or in sparse tufts, particularly noticeable on the middle part of the pre-apical segment (propodite). The posterior border of the basal segment, however, is at most sparsely furnished with short setules. The hair pattern can thus be distinguished from both subspecies of G. zaddachi (p. 23 and Fig. 4). All limbs tend to be somewhat elongate and slender compared with other species of the genus, with the exception of $G$. wilkitskii Birula, in which they are more extremely so, and of $G$. zaddachi which differs very little. Peraeopod 7 shows this tendency at least as much as other limbs, and has been selected for standard measurements. The length $(a)$ of the carpopodite has been compared with (b) its width at the first proximal spine group, and with (c) the length of the basal segment. The ratio of $a: b$ is 4.0 to 4.5 ; of $a: c$ is 0.75 to 0.80 . The last ratio is lower in other species considered here; the first lower in all but zaddachi. The telson, in conformity with the limbs, is also relatively elongate. In adult males the length of one arm is $2.4-2.5$ times its greatest width (in immatures and very young males it is still of more normal proportions with the ratio at about $2 \cdot 0$ ). Uropod 3 inner ramus is typically subequal in length to the outer ramus: more precisely, it is typically $96-99 \%$ the length of the first segment of the outer ramus. No other marine or brackish water Gammarus in British waters shows this condition, and only occasional large specimens of $G$. zaddachi salinus even approach it (p. 29). But some populations, especially those subjected to reduced salinity, have an appreciably shorter inner ramus, which may remain as low as $85 \%$ in well-developed adults. This variation, whether genetic or environmental, is best thought of as an arrest of the differential growth of the inner ramus; since the latter starts much shorter than the outer ramus and normally steadily catches up on it, or nearly so, during the immature phases. The urosome segments dorsally are characteristically strongly raised and laterally compressed in the median line. The elevations are angulate, those on the first two segments forming a right angle in contour, or nearly so (90-I $10^{\circ}$ ). In no other form are these elevations so pronounced.

In practice the relatively long accessory flagellum, the proportions of antenna I peduncle segments, the form of the hand of gnathopod 2 , the dorsal elevations of the urosome, and the long uropod 3 inner ramus, together or 


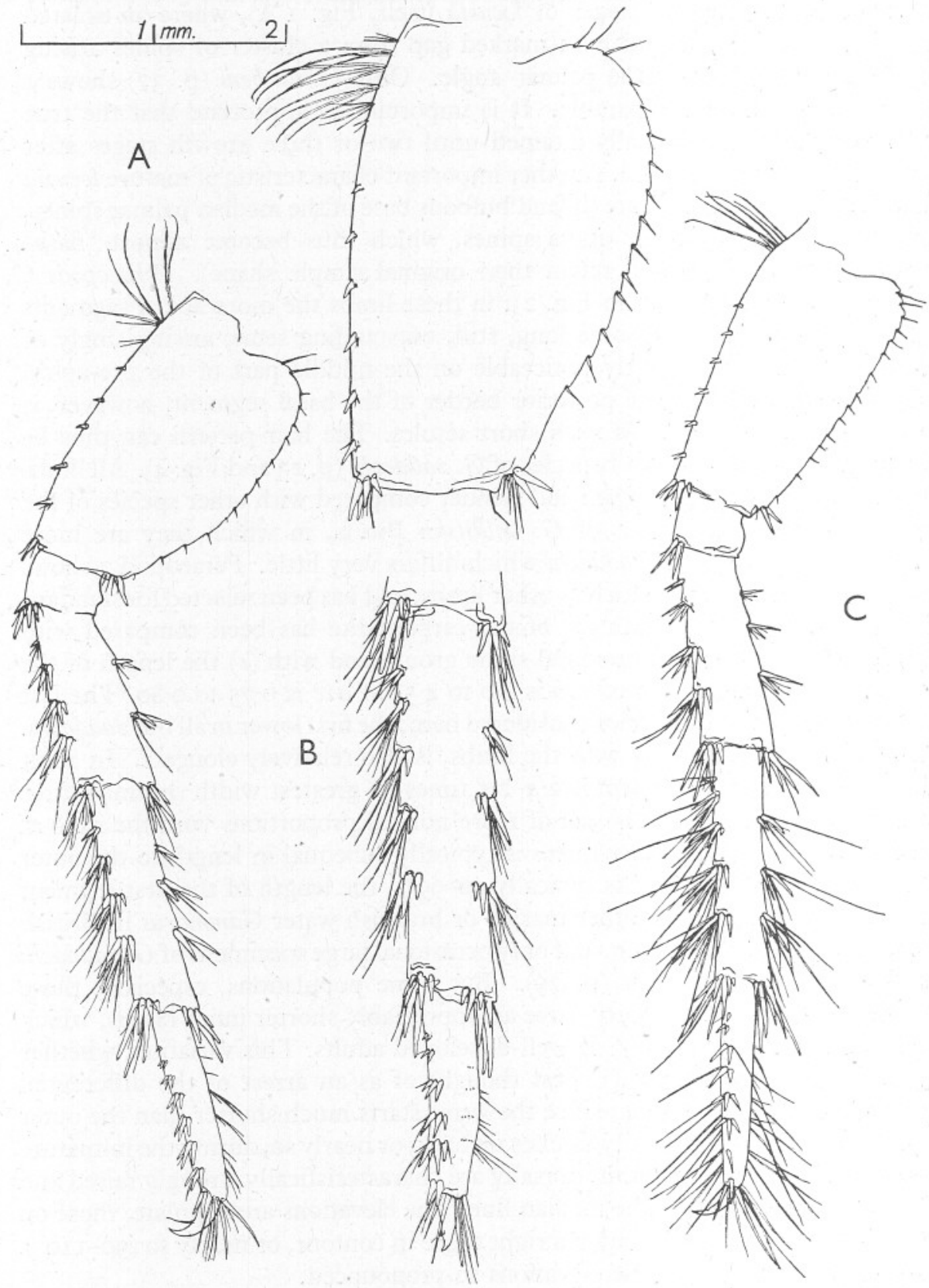

Fig. 2. Gammarus locusta sens.str., peraeopod 7 of male (coxopodite omitted). A, Saltash, River Tamar, 5. iv. 38 (larger specimen than in Fig. I). B, Plymouth Sound, I2. xi. 06 (same specimen as in Fig. I), middle segments omitted. C, variety from the Fleet, Dorset, near Langton Herring, I4. xi. 37. 
even individually provide quick means of identification. The sparseness of the hairs on antenna I peduncle ventrally provides a critical distinction from G. zaddachi. Good specific characters also show in the shorter head, the sharply angulate ventral corner of its lateral lobe, the elongate anterior coxal plates, the deep and subrectangular ventral portion of coxal plate 4 , and the much produced and pointed inferior angles of epimera 2 and 3 . In fresh material the presence of orange pigment spots on the mesosome segments (see below) is also diagnostic, though in larger adults these may be reduced, or absent, or obscured by dense epidermal pigmentation.

\section{Adult female}

Most of the characters given for the adult male apply equally to the female. The description has only to be modified in respect to (I) characters which are directly concerned in sexual dimorphism, e.g. the presence of brood-plates, and the structure of the gnathopod hands; and (2) characters which involve appreciable allometric changes during early maturity, and which remain closer to the immature condition in the more conservative female.

The size attained is much less than in the male: in south-west England a maximum of $20 \mathrm{~mm}$. length (head to apex of telson) contrasts with $28 \mathrm{~mm}$. maximum in the male. The accessory flagellum of antenna $\mathrm{I}$ in the very largest individuals has II segments, when it is $2 \cdot 2-2 \cdot 3$ times the length of peduncle segment 2. More usually the larger specimens in samples are of the order of I5 mm. body length, and these have an accessory of 8 or 9 segments and of length about twice, or slightly less, that of peduncle segment 2. On antenna 2 the flagellum lacks calceoli. The gnathopod hands, though much less specialized than in the male, have still some taxonomic value: the hand of gnathopod 2 is unusually elongate, its dorsal and ventral borders very straight and parallel to each other, and its length always more than twice its distal width (in no other form is a ratio of 2.0 exceeded; in G. zaddachi it is $\mathrm{I} \cdot 65$ to $\mathrm{I} \cdot 8$ ). The median palmar spine is lacking. On peraeopod 3 the hairs are sparser than in the male. The limbs are less slender than in the male adult: in peraeopod 7 the carpopodite is $3.5-3.9$ times as long as broad proximally, and only $0.66-$ 0.70 the length of the basal segment. The telson length attains only 2.25 the greatest width of one arm (though this is still longer than in related species except G. wilkitzkii). The urosome elevations are not quite so pronounced as in the male. The body pigmentation, though variable, is usually heavier, a deep blackish blue colour, with pale bands on the antennae, being common. The eggs are relatively small (see below), and the numbers in one batch relatively large: as many as 235 have been taken from a specimen of $20 \mathrm{~mm}$. length, and 230 from one of $16 \mathrm{~mm}$.

In mixed samples the female locusta is at once distinguished from zaddachi by its sparse antennal hairs, its more elevated urosome segments and its elongate gnathopod 2 hand. 
Table I. Dimensions of Eggs in GAMMARUS LOCUSTA AND ZADDACHI

Gammarus locusta

\begin{tabular}{|c|c|c|c|c|c|}
\hline & $\begin{array}{l}\text { Length } \\
\text { of female } \\
\text { mm. }\end{array}$ & $\begin{array}{c}\text { Size of } \\
\text { brood }\end{array}$ & $\begin{array}{l}n=\text { no. of } \\
\text { eggs } \\
\text { measured }\end{array}$ & $\begin{array}{c}\text { Mean } \\
\underset{\text { length }(l) \times \text { width }}{ }(w) \\
\mathrm{mm} . \times \mathrm{IO}^{-1}\end{array}$ & $\begin{array}{l}\text { Calculated } \\
\text { volume } \\
\text { cu.mm. } \times \text { IO }^{-2}\end{array}$ \\
\hline
\end{tabular}

Newly laid and early development stages

$\begin{array}{lrrll}8 & 23 & 22 & 4.429 \times 3.691 & 3.16 \\ 8 & 14 & 13 & 4.848 \times 3.632 & 3.35 \\ 8.5 & 22 & 22 & 4.669 \times 3.822 & 3.57 \\ 8.5 & 25 & 23 & 4.810 \times 3.791 & 3.62 \\ \text { I0 } & 44 & 40 & 4.678 \times 3.792 & 3.52 \\ \text { I6 } & 230 & 40 & 4.502 \times 3.668 & 3.17 \\ \text { I3.5 } & 57 & 40 & 4.632 \times 3.786 & 3.48 \\ \text { I5 } & 163 & 25 & 4.614 \times 3.981 & 3.83 \\ \text { I2 } & 68 & 40 & 4.630 \times 3.938 & 3.76 \\ \text { I0 } & 84 & 83 & 4.735 \times 3.916 & 3.80 \\ \text { I0 } & 29 & 23 & 4.842 \times 3.958 & 3.97 \\ \text { I0 } & 12 & 9 & 4.96 \times 3.91 & 3.97 \\ \text { I0 } & 24 & 23 & 4.797 \times 3.617 & 3.29 \\ \text { I3.5 } & 135 & 50 & 4.746 \times 4.018 & 4.01 \\ 9.5 & 28 & 28 & 4.857 \times 3.986 & 4.04 \\ \text { I0 } & 29 & 27 & 4.836 \times 4.003 & 4.06\end{array}$

Intermediate development stages

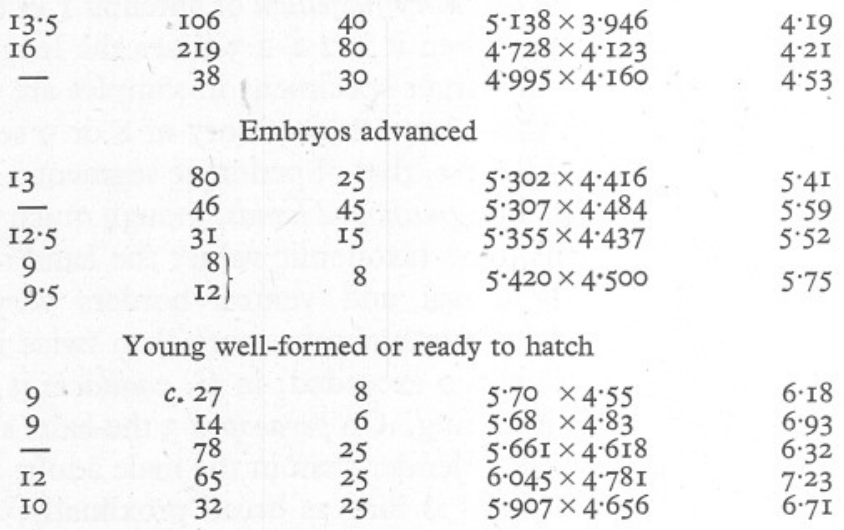

Index to samples from which females were taken:

a, River Tamar, Thorn Point, 22. vi. 39.

$b$, River Tamar, Thorn Point, 9. x. 45 .

c, River Tamar, Ernesettle, r. iii. 38 .

$d$, River Tamar, Henn Point, 5. iv. 38 .

e, River Tamar, St John's Lake, 5. v. 38.

$f$, River Plym, Laira Bridge, 23. xi. 46.

$g$, River Erme, near mouth, 8. ii. 39.

$h$, River Avon (South Devon), I6. v. 38.

$i$, River Avon (South Devon), 8, i. 39.

$j$, River Avon (South Devon), 20. v. 46.

$k$, Kingsbridge Estuary, Blank's Mill Creek, 22. i. 39.

$l$, Kingsbridge Estuary, Salcombe, viii. 45 .

$m$, Brancaster, Norfolk. 


\section{TABLE I (continued)}

\section{Gammarus zaddachi *}

\begin{tabular}{|c|c|c|c|c|c|}
\hline Sample & $\begin{array}{l}\text { Length } \\
\text { of female } \\
\text { mm. }\end{array}$ & $\begin{array}{l}\text { Size of } \\
\text { brood }\end{array}$ & $\begin{array}{l}n=\text { no. of } \\
\text { eggs } \\
\text { measured }\end{array}$ & $\begin{array}{l}\text { Mean } \\
\text { length }(l) \times \text { width }(w) \\
\mathrm{mm} . \times \text { Io }^{-1}\end{array}$ & $\begin{array}{l}\text { Calculated } \\
\text { volume } \\
\text { cu.mm. } \times \text { IO }^{-2}\end{array}$ \\
\hline \multicolumn{6}{|c|}{ Newly laid and early development stages } \\
\hline$a$ & - & 12 & 8 & $5.42 \times 4.44$ & 5.59 \\
\hline$a$ & 一 & I9 & I7 & $5.393 \times 4.659$ & $6 \cdot 13$ \\
\hline$c$ & II & 44 & 44 & $5.573 \times 4.720$ & 6.50 \\
\hline$c$ & 10.5 & 20 & 20 & $5.720 \times 5.080$ & $7 \cdot 73$ \\
\hline$c$ & 12 & 22 & $2 I$ & $5.989 \times 5.067$ & 8.05 \\
\hline$c$ & II & 22 & 20 & $5.856 \times 5.120$ & 8.04 \\
\hline$i$ & IO & 32 & 32 & $5.680 \times 4.725$ & $6 \cdot 64$ \\
\hline$h$ & I3 & 62 & 25 & $5.594 \times 5.005$ & $7 \cdot 34$ \\
\hline$k$ & 9 & 20 & I9 & $5.726 \times 4.855$ & $7 \cdot 07$ \\
\hline$k$ & $9 \cdot 5$ & 22 & 22 & $5.855 \times 4.800$ & 7.06 \\
\hline$k$ & 9.5 & $3 I$ & 29 & $5.639 \times 4.935$ & $7 \cdot 19$ \\
\hline \multicolumn{6}{|c|}{ Intermediate development stages } \\
\hline$a$ & 一 & 7 & 3 & $5.84 \times 4.96$ & $(7 \cdot 52)$ \\
\hline$h$ & 7 & I4 & II & $6.044 \times 4.909$ & $7 \cdot 63$ \\
\hline$i$ & Io & 33 & 32 & $5.898 \times 5.065$ & $7 \cdot 92$ \\
\hline$i$ & c. IO & 29 & I9 & $5.924 \times 5.040$ & $7 \cdot 88$ \\
\hline$i$ & - & 32 & 28 & $5.880 \times 5.286$ & $8 \cdot 60$ \\
\hline$g$ & - & I4 & 10 & $6.347 \times 5.184$ & 8.93 \\
\hline
\end{tabular}

Embryos advanced or young well formed

$\frac{7}{7}$
IO.5
II.5
I $3 \cdot 5$
$9 \cdot 5$

II 5

\begin{tabular}{ll}
37 & \\
I4 & \\
45 & 35 \\
\hline 25 & 3 \\
\hline
\end{tabular}

$6.24 \times 5.51$

Young about to hatch

$\begin{array}{llll}3 I & \text { I3 } & 7.92 \times 5.60 & \text { c. I3.0 } \\ 40 & \text { IO } & 7 . \mathrm{I} 20 \times 5.944 & \text { I3.I7 }\end{array}$

* All specimens belong to subspecies salinus (see p. 20 ).

\section{Measurements of eggs}

A number of measurements of batches of eggs from females of locusta and zaddachi salinus are given in Table I to show the contrast between the two forms. Individual measurements were made in units of $0.008 \mathrm{~mm}$. From the greatest $(l)$ and narrowest $(w)$ diameters, a value representing the volume has been calculated from the formula $l \times w^{2} \times \frac{1}{6} \pi$. It will be observed that the volume is about $0.55-0.6$ that of $G$. zaddachi eggs at comparable stages of development. If there is any increase in size of egg with size of parent, this must be very small and negligible compared with other sources of variation. On the other hand, as is well known, the average number of eggs in one batch tends to increase with the size of the parent. The young at extrusion are correspondingly smaller than in G. zaddachi. 


\section{Immature}

Almost from the time of hatching a small cluster of reddish orange pigment globules is present on several of the peraeon segments. These are situated on segments $2-7$ in the body wall near the base of each limb (Fig. 3). Similar, usually more elongate and more diffuse, patches occur on the metasome, but these are common to several species of Gammarus and Marinogammarus. The presence of these coloured spots on the peraeon is diagnostic of Gammarus locusta. As the young and immature are otherwise colourless and translucent, the spots are very obvious in living and freshly preserved specimens. Though after maturity these pigment spots may be reduced or obscured, they are almost constantly present during immaturity, and provide an excellent means of identifying fresh material, particularly in sorting, for example, mixed populations of locusta and zaddachi. This is an example of a character which might

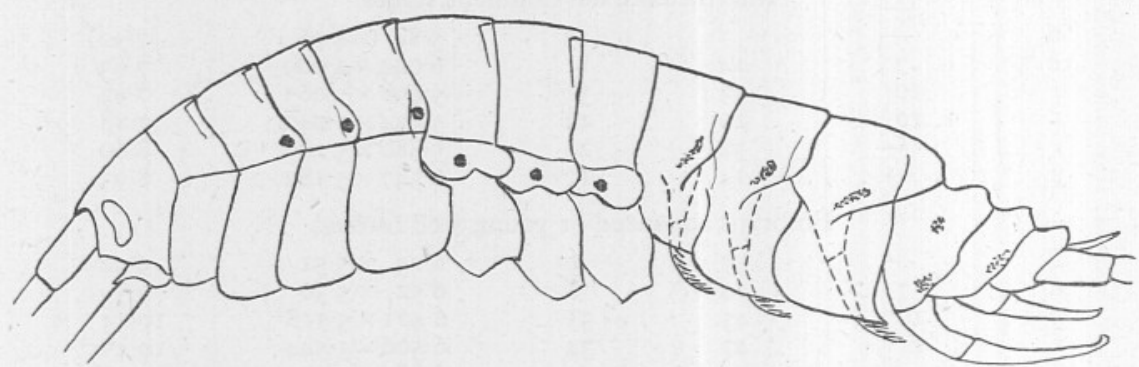

Fig. 3. Gammarus locusta sens.str., body in side view, semi-diagrammatic, to show the position of the orange pigment patches in the body wall. The patches on peraeon segments 2 to 7 , which are diagnostic of this species, are shown as rounded black spots.

be thought to be of low taxonomic grade, but which has proved very reliable in practice.

By the time the immature phase is about half-way through, locusta can be distinguished from other species by various structural features. Already there are indications of a relatively long accessory flagellum, raised urosome elevations, and produced epimera. The inner ramus of uropod 3 is long enough to distinguish it readily from that of a Marinogammarus. Gammarus duebeni is already isolated by the conspicuous produced posterior angles of peraeopod 7 basal segment. The main structural difference from zaddachi at this stage is in the hairs on the ventral surface of the antennal peduncles, which in zaddachi are by now longer and more numerous.

While male characters are developing in the maturing animal, until the stage at which the fully mature form is reached (two or three stages after functional maturity), the hand of gnathopod 2 is still of a somewhat generalized type (Fig. IA). The median palmar spine has appeared, but, as in other species at this stage (and in most throughout life), it is still separated by a gap from 
the spines at the palmar angle, and is not fully truncated distally. Other heterogonic changes are going on at this time, and in very young males comparative measurements may not yield ratios found to be characteristic of the full adult. For example, values nearer those of the female are found for the relative lengths of carpopodite 7 and the telson. In the female the relative length of the gnathopod 2 hand increases from $2 \cdot 0$ to about $2 \cdot 3$ during the first stage of maturity.

\section{Notes on variation within the species}

Apart from adult body pigmentation and average size, the character which perhaps varies most noticeably in normal populations concerns the development of hairs on the limbs. This variation, however, is usually only evident after close inspection, and its range is limited. It seems to apply most to those limbs and side-plates where the total number of hairs is at best never large. For example, a sample from the north Norfolk coast near Brancaster is uniformly hairier, on all peraeopods and on the pleon, than Devon populations. But often within a single population quite noticeable differences occur between individuals of comparable stages of development. Though this matter deserves closer study, the general fact is clear enough, and shows that locusta is no exception to the rule that the development (i.e. number in a cluster, and length of individual hairs) is always subject to variation in a Gammarus species, perhaps sometimes as a more or less direct effect of environmental factors or nutrition, though such an effect has still to be demonstrated experimentally.

Among marine populations an interesting variation has been observed in a sample collected by Mr G. I. Crawford in Whitsand Bay, November I934, by dredging in shallow water offshore. In one sample (5. xi. 34) the males have very dense setation on antenna 2 and peraeopod 3, and the longer hairs are much curved. Except that the elevations of the urosome segments are somewhat rounded and less compressed than usual, other characters are typical of the species. In a second sample of over 300 (dredged in weed, I6. xi. 34), which contained adults of all sizes, actively breeding, the same features are shown, but the male hairs are not quite so dense and only some of the hairs are curved.

It is, however, among populations living under recognizable atypical conditions that variations are most frequently observed. Some examples from brackish waters can be given.

At the limit of penetration into estuaries, particularly if conditions are deteriorating, as with the onset of winter, animals seem subject to inhibition of growth. Maturing individuals are smaller than usual, and often have a somewhat shortened uropod 3 inner ramus (retention of an immature character). It appears, however, that they soon die off as the salinity drops, and do not survive long enough to produce a persistent modified population. In the continuously habitable parts of estuaries populations resemble those from the 
sea. Those living in turbid water or on muddy bottoms are usually deficient in epidermal pigment, and tend to retain the immature translucent appearance.

In some localities where the species is established in water of permanently reduced salinity, persistent atypical characters may be shown. Two instances have come to notice: in the Fleet, Dorset, and New England Creek, Essex.

The Fleet is a shallow stretch of water separating the Chesil Beach from the mainland (see Tansley, 1939, chapter XLII, pls. I55, I56), receiving sea water by tidal action through its narrow connexion with Portland Harbour and fresh water by land drainage. Apparently a fairly steady salinity gradient is maintained through its 9-mile length, the incessant fluctuations characteristic of estuaries being largely lacking. At Langton Herring the water is salt enough to support G. locusta (in November it measured $26 \%$ at low water). Samples collected here on $\mathrm{I} 4$. xi. 37 and 27. iii. 38 show the following characters. (i) Uropod 3 inner ramus short, in adult males only $80-90 \%$ of outer ramus segment I; (ii) hairs unusually dense, especially in the male on antenna 2 peduncle and on hinder peraeopods (Fig. $2 \mathrm{C}$ ), the length and number of the stiff outstanding hairs on the latter being particularly noteworthy; (iii) the spines on ventral border of epimera 2 and 3 unusually strong; (iv) side-plates and basal segments of peraeopods (Fig. 2 C) notably narrow; (v) other segments of peraeopods slender, e.g. carpopodite 7 nearly 5 times as long as wide proximally; (vi) average size of adults below normal. All other features are quite characteristic of locusta; the male gnathopod 2 is in fact rather an extreme locusta type. The orange spots on the peraeon were well developed.

The population from New England Creek, Essex, where the fauna and environment were carefully studied by Howes (1939), is still more aberrant. $\mathrm{Mr}$ Howes kindly sent me his Gammarus for examination, and my report on their characters is given in his paper (p. 4I4). It is definitely a dwarfed population of locusta, presumably surviving from the time the creek was cut off from the sea by a dam. Ample diagnostic features are shown in the elevated urosome segments, the form of the male gnathopods, the deep ventral portion of coxal plate 4, the produced angular corner of the lateral lobe, the lack of long hairs on basal segments of peraeopods 6 and 7 (though the rest of these limbs is unusually hairy), the sparsity of hairs on antenna I, etc. Atypical features recorded were as follows: (i) uropod 3 inner ramus relatively short, between 80 and $90 \%$ of segment I of outer ramus; (ii) hairs unusually dense, even more so than in the Fleet population; (iii) the spines on the ventral border of epimera 2 and 3 in some specimens notably strong; (iv) size much reduced, correlated with which the number of segments in the accessory flagellum did not exceed 8,7 being a frequent number; (v) in one sample containing the most extreme dwarfed and hairy specimens there was a strong tendency for the hairs on the male antenna 2 to become curled. 
It will not escape notice that the variations of these two brackish populations are of a very similar kind. One is tempted to ask whether reduction of salinity alone has not brought about like results in two widely separated localities. It would be very instructive to test the constancy of the characters of populations as these, by rearing in the laboratory under controlled conditions.

Two samples from the shore at Traigh Mor, Barra, Outer Hebrides (coll. K. M. G. Fleming), varied from the normal in the following respects: eye notably broad; hinder peraeopods with long spinose setae; female gnathopods and fore-peraeopods more densely hairy; and body size somewhat reduced.

\section{Material examined}

(Samples involved in population analyses to be dealt with later are marked with an asterisk. Abbreviations: coll., collected by; Coll., collection.)

England and Wales. E. Cornwall: Whitsand Bay, 5. xi. 34, I6. xi. 34, samples dredged in shallow water by G. I. Crawford. E. Connwall and S. Devon: Plymouth Sound, including Cawsand Bay, various samples on different occasions, including a large sample of well-grown adults from a dense 'swarm' in the open water of the Sound, I2. xi. 06 (Plymouth Laboratory Coll.); Estuary of R. Tamar and branches, numerous samples, * from the Hamoaze and St John's Lake upstream to Weirquay and Bere Ferrers. S. Devon: various samples * from the seaward end of the estuaries of R. Plym, R. Yealm, including the Cofflete branch, R. Erme and R. Avon; from the shore at Wembury; from the Kingsbridge Estuary; and from the estuaries of R. Exe and R. Axe. Dorset: The Fleet, at Langton Herring, I4. xi. 37, 27. iii. 38, numerous amongst Zostera hornemanniana in water of reduced salinity; Lulworth Cove, 26. xiii. 37. S. and N. Somerset: Bristol Channel coast at Kilve and Weston (Severn Estuary survey, by R. Bassindale, etc., see references given on p. 39). S. EsSEx: New England Creek, dwarfed population in brackish water (Howes, I939). N. NoRFOLK: sample from Brancaster district, coll. C. F. A. Pantin. NorThumberland: Blyth, ditch from salt pans, 4. vii. 34, coll. Prof. A. D. Hobson, adults, breeding (with G. zaddachi salinus). DURHAM and N.E. Yorks: River Tees Estuary, Tees Survey material* (Alexander et al., I935), several from tidal zone and in tow-nettings. IsLE of MAN: Port Erin, shore and 4-5 fathoms, Port St Mary, in weeds near L.w., ix. 38 , coll. G. I. Crawford.

Scotland. PERThSHIRE and Fifeshire: R. Tay Estuary, Tees Survey material, * one male from tidal zone of Section XI. Clyde IsLes: Cumbrae, Kames Bay, R. Elmhirst Coll., 6. iv. 34, a few adults. ARgylLSHIRE: Clachan Strand, under weed, Prof. A. D. Hobson Coll. InNer Hebrides: S. Rona, vii, viii. 37, Prof. A. D. Hobson Coll., 'Dry Harbour', Io fathoms, 4 ôे $^{\star}$, I imm., 'Big Harbour', shore, small ô and +o, I imm.; Raasay, viii. 37, A. D. H. Coll., 
Churchton Bay, 2-3 fathoms, a number, 'Stephenson's Bay', I $\delta^{\wedge}$ (with G. zaddachi); Isle of Muck, A. D. H. Coll., in eight samples, from Gallanach, I. ix. 36, I7. viii. 39, Port Chreadhair, vii. 38, Rudha Caem na Caraich, 30. vii. 38, I6. viii. 39, etc. OUter Hebrides: Barra, coll. K. M. G. Fleming, vii. 36, 37, Traigh Mhor, L.W.s.T., two samples with adults of small average size.

Belgium. Ostende, Bassin de Chasse, c. 900 ô ${ }^{\circ}, 870$ 우 and $400 \mathrm{imm}$., in 7I samples (in collections identified for the Brussels Museum in Jan. 1939).

\section{Gammarus zaddachi Sexton}

This is an important species in the economy of estuarine and other brackish waters, being very widespread in spite of the discontinuity of its habitats, and usually plentiful provided there is adequate cover of some sort and, apparently, an adequate oxygen concentration. It is one of the dominant members of the fauna in those parts of estuaries where the salinity fluctuations are greatest, and so most 'rigorous' to life.

The confusion over this species in the past has been considerable. Even after it had been described (Sexton, I9I2), British material was still being overlooked and recorded as duebeni in fresher habitats, or as locusta in more saline waters. Continental authors have not helped matters, either from attempts to sink the species, or, sometimes, in their failure to appreciate its most reliable diagnostic characters.

Sexton (1942) has followed up her careful original description with a further detailed account which emphasizes (I) the differences between zaddachi and related species with which it may possibly be confused, and (2) the differences between the two extremes of variation, i.e. between a very hairy 'fresh-water' form inhabiting the lower reaches of the Elbe and Weser, and a sparsely haired, more spiny, 'true brackish water' form living in estuaries and along the coast of East Prussia. The 'fresh-water' form is figured for the first time. The presence of intermediate forms linking the two extremes is stressed. A complete and very valuable summary of the past literature referring to the species is also given. Those who wish to study G. zaddachi from any aspect are fortunate in having Sexton's admirable descriptive papers as a background.

There should no longer be any reason for confusions which have invalidated species identifications in the past, at least as concerns Britain. I have to concede that systematists may have a more difficult task in some other parts of Europe. For example, it is now clear that $G$. 'locusta' in west Norway mainly belongs to a northern race which, though larger, is very close to G. zaddachi in its body proportions and gnathopod characters (see below); while, judging from published data on Gammarus populations from the west Baltic, I can only conclude that populations of $G$. locusta which occur there in low salinities fail 
to show some of the marked characteristics found in the typical form inhabiting the North Sea, etc. $†$

The need for giving yet further attention to the taxonomic characters of G. zaddachi arises from several causes. (I) Sexton's descriptions and drawings are based primarily on German material: the extent to which they strictly apply to British populations had to be examined. (2) The descriptions are mainly devoted to adult male characters: more complete knowledge of the female and immature had to be acquired, and a clearer picture obtained of heterogonic changes which take place during early maturity. (3) Most important of all, the variation which occurs within the species, at least some aspects of it, demanded attention; and one result has been to show that the species can be split into two well-defined types, as was apparent at an early stage in this investigation.

In erecting two subspecies, I am anxious to be able to refer to type specimens and type localities. Since no type of the species has ever been designated, it is necessary to rectify this omission first. Sexton's original description (I9I2) covers the species as a whole: selection must therefore be made from the samples she examined and described. For various, reasons I choose the samples of the Hamburg 'fresh-water' population to designate the type of the species (Sexton, I9I2, p. 660, 'Hamburger Wasserleitung', 5 specimens; Hamburger Wasserleitung, Samuelson, 7 I specimens; Hamburg Mus. Coll.). These automatically become the types of the relatively 'hairy' subspecies, namely, G. z. zaddachi, which is now recognized as embracing a widespread form which colonizes brackish waters of low salinity, as well as fresh waters to a much more limited extent. Sexton's 'pure brackish water form' becomes subspecies salinus, with the type from the estuary of the River Weser: 'Bremerhaven, Herr Klie; Alterhafen, x. I9II' (Sexton, I9I2, p. 660, pls. Ixxiii, lxxiv). G. z. salinus is a characteristic estuarine form in west Europe, intolerant both of full-strength sea water and of water which is fresh or very weakly brackish. It is possible that further investigation will show that the so-called ' locusta' from northern waters, ${ }^{1}$ though essentially a marine form, should be included within zaddachi as a third subspecies. ${ }^{2}$

† Segerstråle (pp. 219-44) has now made it quite clear why there has been so much confusion between locusta and zaddachi in Scandinavia and in the Baltic. His newly-defined (z.oceanicus) is in some ways intermediate between zaddachi salinus and locusta sens.str.

1 Excluding $G$. setosus Dement., which is clearly a separate species. See also the footnote on p. 7 .

${ }_{2}$ This is precisely the conclusion to which Segerstråle comes (pp. 223 et seq.). The northern marine subspecies occurs also in the Baltic as well as salimus, and I find that some of Sexton's original 'brackish water' form belong to it, as do also some British specimens from Scotland which I had formerly included under salinus. 


\section{THE DifFerences BETWEEN THE TWO SubSPECIES}

\section{G. z. zaddachi}

Figures in Sexton, I942: fig. I $a$, pl.i(figs. I-7), pl. ii(figs. IO-I4)

Absolute differences

Peraeopods 6 and 7 (setation)

Urosome and telson (setation)

Epimera 2 and 3 numerous hairs (Sexton, I942, pl. ii, fig. 13)

Posterior distal angles a little less

\section{G. z. salinus}

Figures in Sexton, I912, I9I3, and I942: fig. I $b$, pl. i (figs. 8-9), pl. ii (figs. I5-I8)

Much more glabrous, the more distal segments with only a few moderately long hairs at most, and the basal segment posterior margin with short setules. Conspicuous tufts on distal segments lacking. Spine groups more evident owing to sparsity of hairs and to greater average length of spines (Fig. ${ }_{4} \mathrm{C}$; see also Sexton, I942, pl. ii, figs. I5-I7)

With a few shorter hairs only, which are rarely.longer than the spines with which they are associated (Sexton, I942, pl. ii, fig. I8)

Angies rather more acutely produced (Fig. 6 B). Posterior margins of both epimera with not more than one or two setules Epimeron 2 posterior margin with a row of several short setules (in adult male at least) cutely produced (Fig. $6 \mathrm{~A}$ ).

N.B. The characters given below regarding the length of the accessory flagellum and of uropod 3 inner ramus may provide absolute distinctions if animals from the same region are compared.

\section{Average differences}

General body colour of adult

Antenna I accessory flagellum

Uropod 3 inner ramus
Body pigment, when normally developed, distinctly dull greenish (with darker bands marking the boundaries of the segments); never infuscated

On average with one segment less (4-7 segments, according to age, in adults); somewhat shorter than peduncle segment 2 , or at most about equal to it in older adults (see pp. 26-7)

Relatively shorter; in majority $(90 \%)$ of British animals it is $0.67-0.76$ length of segment I of outer ramus (see pp. 28-30)
Body pigment, when developed, less greenish and more brownish (with obscurer banding); sometimes much infuscation may be found in the females (as in G. locusta)

On average with one segment more (5-9 segments, according to age); at maturity about same length as peduncle segment 2, becoming distinctly longer in older adults (see pp. 26-7)

Relatively longer; mainly (95\%) $0.78-0.89$ length of segment $I$ of outer ramus (Fig. 6 D) 


\section{The DifFerences BETWeen the TWo SubSPECIES (continued)}

\section{G. z. zaddachi}

Urosome dorsal spines

Telson spines

Peraeopod distal segments

Gnathopod 2 hand of male

General setation

Habitat

\section{General setation}

The typical subspecies tends generally to be more 'hairy' than salinus, both with regard to number of tufts, number of hairs in each tuft, and to the length of individual hairs. (On any given limb or somatic plate one of these features may be more relevant than the others.) It is now a matter of experience that 'hairiness' within a species of 'Gammarus is subject to local variation (e.g. the examples given for $G$. locusta, pp. I5-I7, and similar behaviour in G. duebeni could be quoted), some of which may well be phenotypic, though this has still to be demonstrated experimentally. Indeed, there are some interesting variations within both subspecies of zaddachi, as here delimitated, more especially as between different areas or habitats. It is therefore necessary, on a priori grounds, to be especially cautious in attributing too great a taxonomic significance to differences in setation. On the other hand, the degree to which variation occurs in well-defined species appears to be subject to distinct 
limitations, and the general pattern and other features of the setation may provide useful diagnostic characters. This statement is necessary in view of Sexton's suggestion (e.g. 1942, p. 576) that characters affecting epidermal outgrowths should be treated in a different category from 'structural' characters (in which is included the shape of different parts and their relative proportions). From a purely morphological standpoint there seems no necessity for this opinion; while from a taxonomic approach it is enough to treat characters on their merits. By this is meant that when setation characters are found to present constant differences, these are of equal value with so-called 'structural' characters which show differences of comparable degree; while, conversely, both 'structural' and setation characters may equally be subject to a degree of variation which renders them unreliable taxonomically.

The variation in general 'hairiness' in G. zaddachi is known to be great, decidedly greater than in related species. But the range of habitats is also unusual, especially with regard to salinity. Sexton (I9I2, I942) has emphasized the close correlation between the development of hairs and the salinity of the habitat, the hairiest examples having been found in fresh water, and the most glabrous in estuaries or brackish lagoons. Her interesting observations serve at least as a warning that variation in hairiness may be mainly phenotypic.

However, new light has been thrown on this subject by detailed study of zaddachi populations from Britain, where the difference between the more extreme hairy and hair-deficient individuals is comparable with that found on the continent. For the first time field study has been supplemented by experimental data. Present conclusions can be summarized as follows. (I) The variation in hairiness is not strictly continuous, but centres round two main types-representing the two subspecies as here defined. (2) The setation of the hinder parts of the animal shows a strong discontinuity between the two types, and provides a safe absolute means of separating them. (3) Estuarine populations of each subspecies, considered separately, fail to show any grading of hairiness correlated with the salinity gradient. (4) Since, also, the two types each retain their essential setation characters when reared at different salinities, the variation must be far from wholly phenotypic. (5) Since the two types are incapable of cross-breeding with each other, there is genetic difference between them; and on this genetic difference part of the variation in hairiness, observed in the species as a whole, must depend.

The use of certain setation characters has thus proved justified. At the same time it is necessary to be more precise than to consider hairiness of the animal as a whole. Variation in the setation of the hinder peraeopods, especially of the 5 th, of the urosome, and of the telson, shows the greatest discontinuity, and is of special taxonomic value. This will be described in the next section. By contrast, the setation of the antennae (see Fig. 5), gnathopods, peraeopods 3 and 4 , etc., while on the average showing fewer and shorter hairs in salinus, is 
too variable in different populations of each subspecies to be of comparable taxonomic value; though of potential importance in distinguishing some geographical or habitat forms. It is possible, for example, that the pure freshwater populations may always be recognizable by a maximum development of hairs at the base of antenna I flagellum.

\section{Setation of peraeopod 7, urosome and telson}

Sketches of peraeopod 7 for adult males of both subspecies are given in Fig. 4. The essential features which separate the two forms are as follows:

G. z. zaddachi. (I) Basal segment with a row of hairs posteriorly, often of varying lengths, but with at least half of them distinctly long, often several times longer than the intervals between successive hairs. The number increases with the growth of the limb, but at comparable sizes this is somewhat greater than that of the short setules in salinus. (2) The hair-tufts on the mero-, carpoand propodites are very conspicuous in the length and density of the hairs: the longer hairs in each tuft are at least twice the length of the longest spines of the associated group, and each tuft (excluding a few of the smallest) has at least 5 hairs, usually 8 or more. The posterior tufts on the propodite are at least half the length of the propodite itself.

G. z. salinus. (I) The posterior margin of the basal segment is provided only with short setules. These may be very short, or about as long as the interval between successive setules, usually distinctly shorter than the intervals. Normally they are more sparsely distributed than the hairs in the typical subspecies. (2) On the more distal segments the spines are more evident, partly because they tend to be somewhat longer, but chiefly because they are not overshadowed by the hair tufts. The latter are much sparser, reduced to I or 2 hairs (at most 3 or 4 ), of which only a single hair here and there may appreciably exceed the length of the associated spines. The posterior tufts on the propodite are similarly reduced, usually to I or 2 short hairs, but when less reduced the longest hair does not exceed one-third of the length of the propodite itself.

The spines in salinus have been noted as longer, as a rule, but it is doubtful whether the average number per group is greater.

Within each subspecies there is a limited amount of variation, as already indicated. For example, in G. z. zaddachi, both the length of the hairs and the density of the tufts appear to be at a maximum in the Hamburg fresh-water population described by Sexton (1912; 1942, pl. ii, fig. I2), but these can be matched by the 'hairiest' specimens found in British brackish waters. In Britain the populations from the Tay and Tees estuaries are on the whole distinctly 'hairier' than those from South Devon estuaries. The hairs of the latter, however, cannot be still further reduced by rearing in water of increased salinity. It seems that in them the limit of variation towards reduction of hairs in G. z. zaddachi has been reached. 


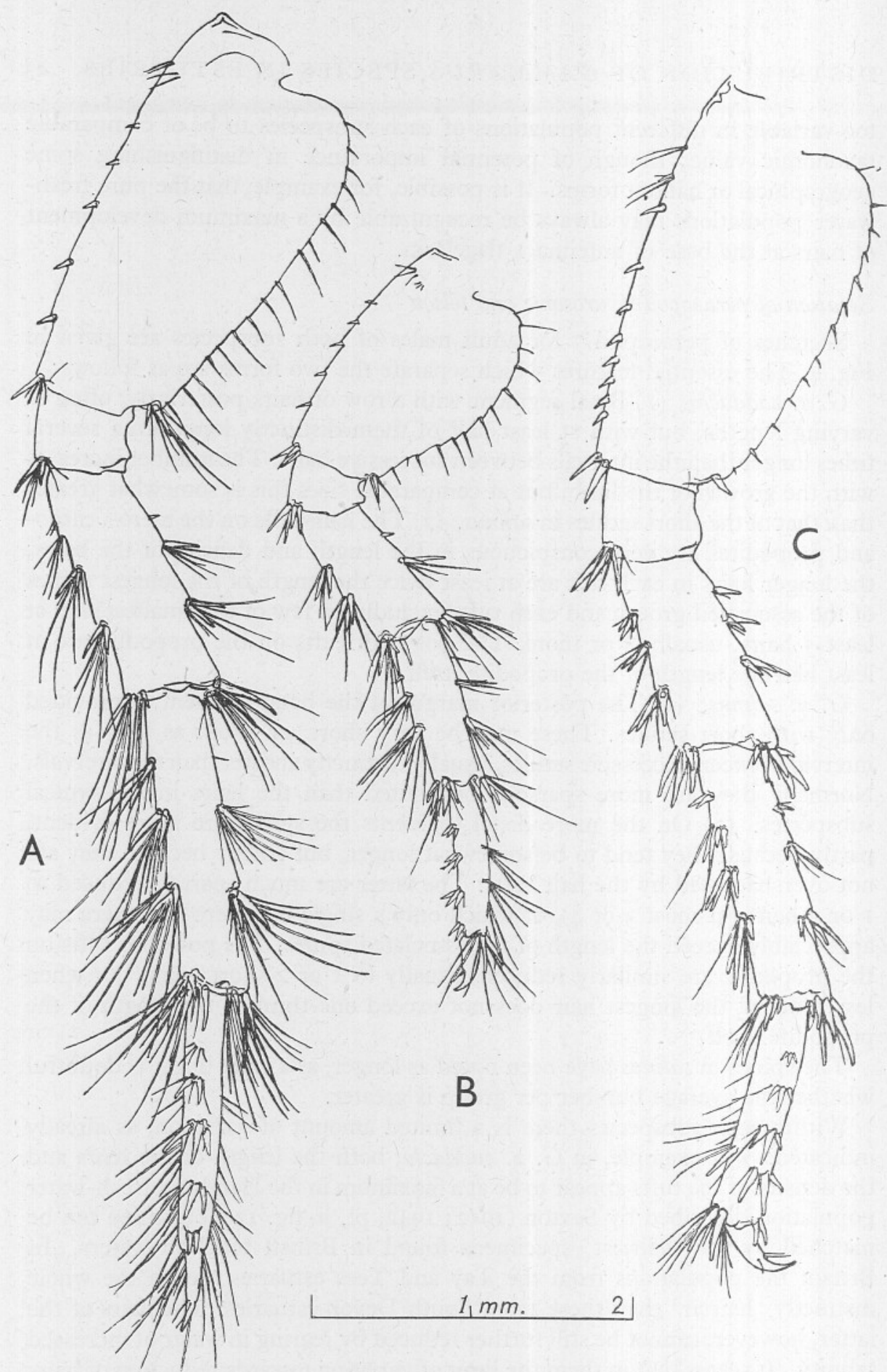

Fig. 4. Gammarus zaddachi, peraeopod 7 (coxopodite omitted). A, subspecies zaddachi, male (no. 52), Cofflete creek, River Yealm, South Devon, 3. vi. 46 (from moult). B, female of same, from the same sample (from moult). C, subspecies salinus, male, I8 mm., River Avon, South Devon, I4. v. 46. 
A
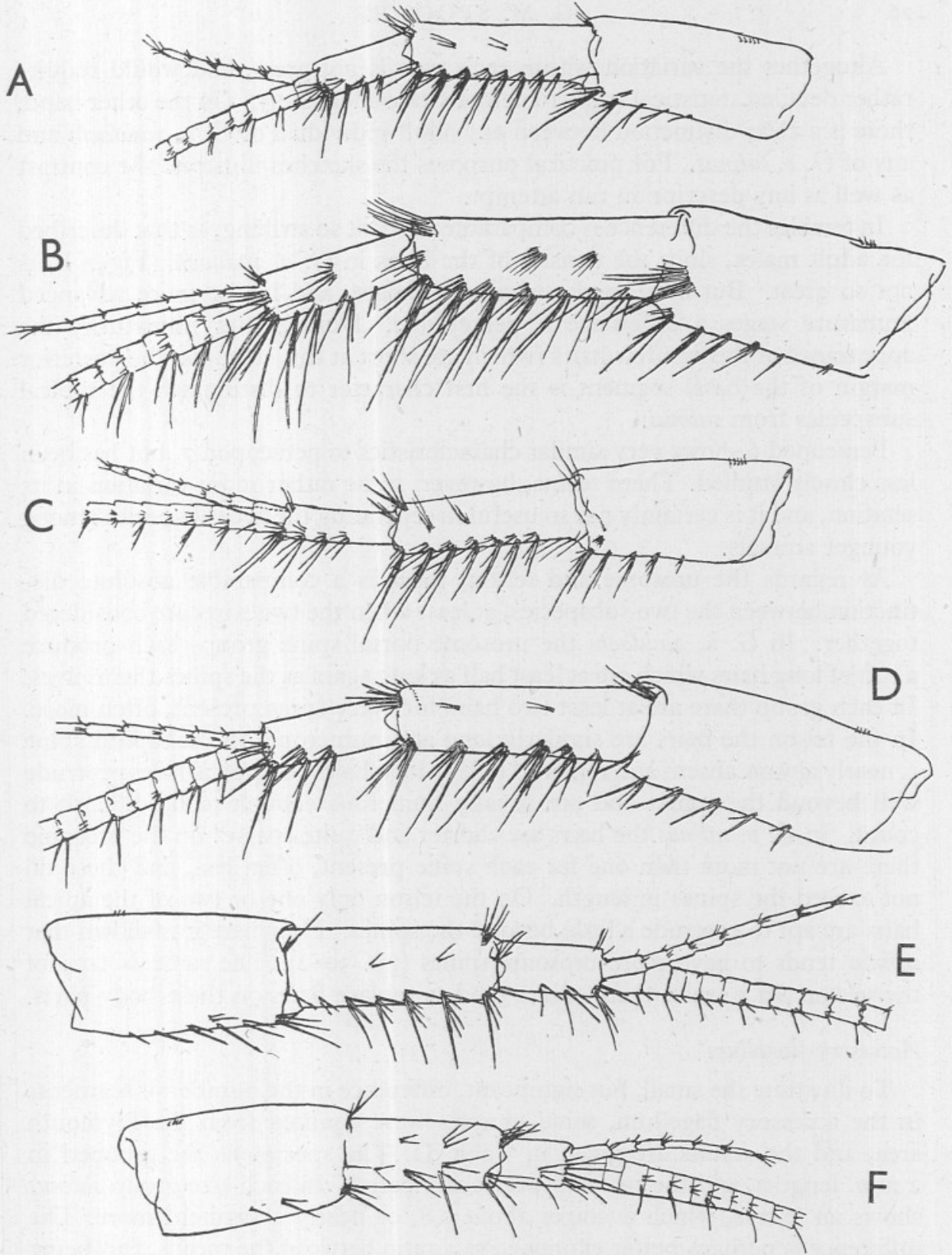

Fig. 5. Gammarus zaddachi, peduncle of male antenna I; A-C, subspecies zaddachi, D-E, subspecies salinus. A, St John's, River Tamar, 28. iii. 40, $18 \mathrm{~mm}$. B, River Tees, $21 \mathrm{~mm}$. C, Cofflete creek, River Yealm, South Devon (from moult). D, River Severn, 23. vi. 39, 2I mm. E, River Avon, South Devon, I4. v. 46, I8 mm. F, River Tay, section IX. All viewed from inside, except $\mathrm{B}$, in which the bases of the ventral tufts are shown as though seen through the thickness of the segments. (Note, in F, that segments 2 and 3 are relatively short compared with segment $\mathrm{I}$, and the ventral hair tufts, of which there are only two on segment $I$, are relatively sparse. $\dagger$ )

† This compares with the northern subspecies described by Segerstråle on p. 226 . 
Altogether the variation within each type is not great, and would require rather detailed statistical study to demonstrate adequately. On the other hand, there is a clear distinction between any adult individual of $G . z$. zaddachi and any of $G$. z. salinus. For practical purposes the sketches illustrate the contrast as well as any description can attempt.

In females the difference is comparable, but not so striking, as that described for adult males, since the density of the hairs in G. z. zaddachi (Fig. 4 B) is not so great. But even in the youngest females and in the more advanced immature stages a difference is perceptible. During later immaturity the appearance of the first few hairs (which are short at this stage) on the posterior margin of the basal segment is the first character to distinguish the typical subspecies from salinus.

Peraeopod 6 shows very similar characteristics to peraeopod 7 , but has been less closely studied. There seems, however, to be rather more variation in its setation, and it is certainly not so useful in separating the two subspecies among younger animals.

As regards the urosome and telson, there is a comparable absolute distinction between the two subspecies, at least when the two parts are considered together. In G. z. zaddachi the urosome dorsal spine groups each produce a tuft of long hairs which are at least half as long again as the spines themselves. In each group there are at least two hairs for every spine present, often more. In the telson the hairs are similarly long and numerous; the subapical spine is nearly always absent and replaced by $2-5$ long hairs; the apical hairs protrude well beyond the spines and are usually numerous enough to be difficult to count. In $G$. z. salinus the hairs are shorter and quite sparse: on the urosome there are not more than one for each spine present, often less, and these do not exceed the spines in length. On the telson only one or two of the apical hairs are apt to protrude a little beyond the spines. Elsewhere it is shown that salinus tends to have more urosome spines (pp. 30-2). The same is true of the telson. In a sense, then, spines tend to replace hairs on these body parts.

\section{Accessory flagellum}

To illustrate the small, but significant, difference in the number of segments in the accessory flagellum, some samples were counted from the Plymouth area, and the results are given in Table II. The specimens are grouped in $2 \mathrm{~mm}$. lengths, and the two subspecies compared. In each size group salinus shows an excess, which averages about 0.8 , or nearly I segment more. The difference is perhaps better expressed as a ratio between the means, this being about I.I5: I. Thus young mature male salinus have an average excess of 0.6 , and the largest of at least $\mathrm{I} \cdot \mathrm{O}$.

A similar contrast has been observed in samples from other parts of the British Isles. In G. z. zaddachi a total of seven segments is the usual maximum, while a total of nine is not rarely attained in large salinus. 


\section{Table II. Number of Segments in Male Accessory Flagellum}

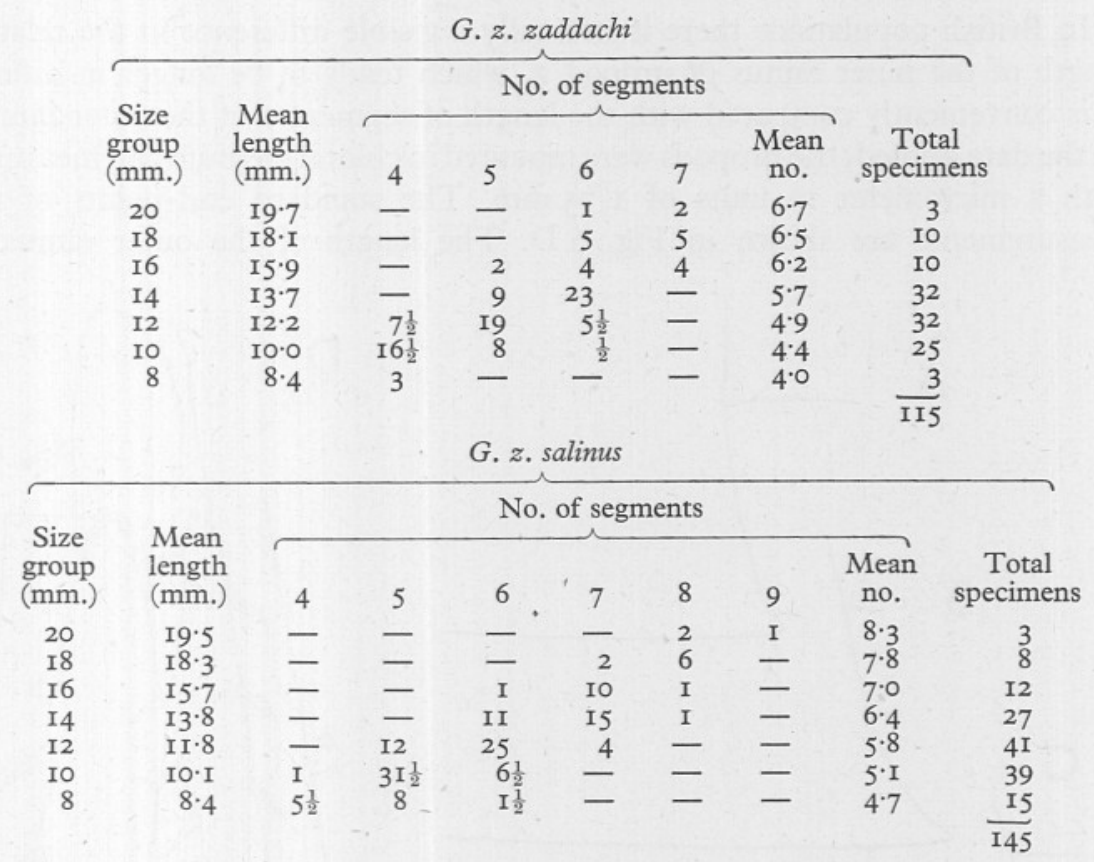

N.B. Half-values are given when right and left sides are different, or when a segment is nearly but not completely divided.

Difference in the number of segments is reflected in difference in length, which can be made relative to another part of the body, and which is thus a more serviceable character. The accessory flagellum is conveniently compared with peduncle segment 2 (reference may be made to Fig. 5). In salinus the two are of about equal length at the onset of maturity, but when the animal is fully mature the flagellum is $25-35 \%$ longer (as shown by micrometer measurements). In the typical subspecies the flagellum is distinctly the shorter at onset of maturity, and increases only to $96-105 \%$, or so, with age. At the start, in British brackish-water animals, it is some $75-85 \%$, soon increasing to the region of $100 \%$; but in four well-grown fresh-water males from Hamburg and Bremerhaven (E. W. Sexton Coll.) values fall between 59 and $80 \%$ only, while comparably short flagella were observed in a sample from Swinemünde, Prussia (Copenhagen Mus. Coll.). It is possible therefore that a greater contrast in this character difference may be found on the continent.

In females the contrast is very much less, at least in Britain. Those of G. z. salinus seldom have an accessory flagellum appreciably longer than peduncle segment 2 . 


\section{Uropod 3 inner ramus}

In British populations there is normally a visible difference in the relative length of the inner ramus of uropod 3 , which tends to be longer in salinus. It is conveniently compared with the length of segment $I$ of the outer ramus. In the data quoted, the uropods were mounted in chloral medium and measured with a micrometer in units of $\mathrm{I} / 75 \mathrm{~mm}$. The standard end-points of the measurements are shown in Fig. $6 \mathrm{D}$. The length of the outer ramus of
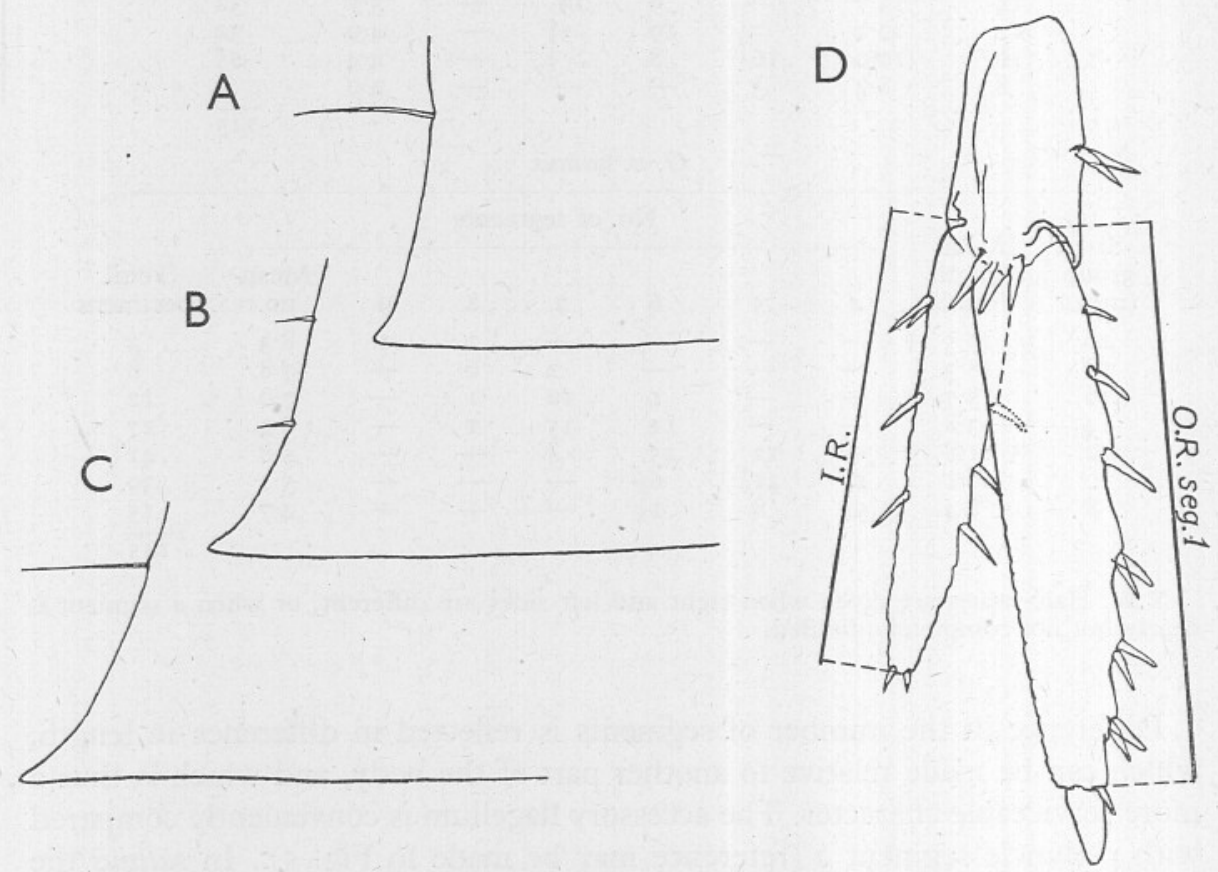

Fig. 6. Examples of the posterior distal angle of epimeron 3, right side, in (A) Gammarus zaddachi zaddachi, (B) G. zaddachi salinus and (C) G. locusta sens.str. (D) G. zaddachi salinus, male uropod 3 , with setae omitted, showing the end-points of measurements on the inner ramus (I.R.) and the first segment of the outer ramus (O.R. seg. I).

segment I gives an absolute length measurement which (unless the limb is regenerating) is a close index of the size of the animal: it averages $I / 7.5$ the body length (measured from head to apex of telson). The length of the inner ramus is expressed as a proportion of it.

In Table III the total results for adult males from south-west Devon are compared. The G. z. zaddachi animals were taken from samples from the Rivers Tamar, Tavy, Plym, Erme, and their branches; the salinus animals from the Avon, and from the Tamar and its branches. Only animals in which the outer ramus segment I was at least IIO units ( $1.47 \mathrm{~mm}$.) are included. 


\section{Table III. Relative Length OF URopod 3 INNer Ramus. G. ZADDACHI FROM SOUTH-WEST DEVON}

Ratio length of inner ramus to that of outer ramus segment $I$

\begin{tabular}{|c|c|c|c|c|c|c|c|c|c|}
\hline & 0.66 & 0.67 & 0.68 & 0.69 & 0.70 & $0.7 \mathrm{I}$ & 0.72 & 0.73 & 0.74 \\
\hline \multirow{3}{*}{$\begin{array}{l}\text { G. z. zaddachi } \\
\text { G. z. salinus }\end{array}$} & 2 & 3 & 9 & 3 & 9 & I3 & I6 & I4 & I5 \\
\hline & - & - & - & - & - & - & 一 & - & \\
\hline & 0.75 & 0.76 & 0.77 & 0.78 & 0.79 & 0.80 & $0.8 \mathrm{I}$ & 0.82 & 0.83 \\
\hline \multirow{3}{*}{$\begin{array}{l}\text { G. z. zaddachi } \\
\text { G.z. salinus }\end{array}$} & 3 & I & 2 & I & I & I & - & - & - \\
\hline & - & - & I & 5 & 4 & II & I7 & 8 & II \\
\hline & 0.84 & 0.85 & 0.86 & 0.87 & 0.88 & 0.89 & 0.90 & $0.9 \mathrm{I}$ & 0.92 \\
\hline \multirow{3}{*}{$\begin{array}{l}\text { G. z. zaddachi } \\
\text { G. z. salinus }\end{array}$} & $\overline{\text { IO }}$ & $\overline{5}$ & $\overline{6}$ & $\overline{4}$ & $\overline{4}$ & $\overline{6}$ & $\bar{z}$ & $\bar{I}$ & \\
\hline & & & Tota & & Iean & & D. & & \\
\hline & $\begin{array}{l}z a d \\
\text { sali }\end{array}$ & & $\begin{array}{l}93 \\
93\end{array}$ & & $\begin{array}{l}718 \\
830 \\
830\end{array}$ & & $\begin{array}{l}0272 \\
0316\end{array}$ & & \\
\hline
\end{tabular}

The mean for the typical form, $71 \cdot 8 \%$, compares with $83.0 \%$ for salinus. The overlap is small, and is smaller still when specimens of the same size are compared, as there is a tendency for the ratio to increase slightly with age.

If the data in Table III are split up according to localities, good uniformity in the component samples is shown. There is no significant difference in the localities involved in each set (Table IV).

\section{TABLE IV. INNER RAmUS Ratios}

\begin{tabular}{lcllrr}
\multicolumn{1}{c}{ Localities for } & & \multicolumn{5}{c}{ Localities for } \\
$\quad$ G. $z$. zaddachi & $n$ & Mean & \multicolumn{1}{c}{ G. . salinus } & $n$ & Mean \\
R. Tamar, St John's & 25 & 0.723 & R. Tamar, Weirquay & 7 & 0.824 \\
R. Plym & 29 & 0.716 & R. Tamar, Cargreen & 26 & 0.831 \\
R. Erme & 22 & 0.710 & R. Tamar, Tamerton Lake & 2 I & 0.829 \\
Misc. (R. Tavy, Tamar, & I7 & 0.727 & R. Tamar, Ernesettle & I9 & 0.824 \\
Yealm) & & & R. Avon & 20 & 0.836
\end{tabular}

Maturing males, represented in size groups 78-109 units, show a comparable difference, though, owing to the heterogony taking place at this stage, the ratio is somewhat lower in each, and the variation is greater (Table V).

\section{Table V. Inner Ramus Ratio in Maturing Males}

$$
\begin{array}{lllc} 
& n & \text { Mean } & \text { S.D. } \\
\text { G. } z \text {. zaddachi } & 28 & 0.700 & \pm 0.0367 \\
\text { G. zalinus } & 56 & 0.808 & \pm 0.0465
\end{array}
$$

The degree to which, after maturity, the ratio may alter with increased size is indicated by the figures in Table VI. There is a definite trend for a small increase which is not altogether negligible. 


\section{Table VI. InNer Ramus Ratio at Different Sizes}

\begin{tabular}{|c|c|c|c|c|}
\hline $\begin{array}{l}\text { Size group } \\
\text { (length outer ramus }\end{array}$ & & dddachi & & alinus \\
\hline mm. units) & $n$ & Mean & $n$ & Mear \\
\hline Over 200 & I & $(0.73)$ & - & - \\
\hline I60-199 & I7 & 0.728 & I4 & 0.842 \\
\hline $135-159$ & 29 & 0.729 & 28 & 0.836 \\
\hline IIO-I 34 & 46 & 0.709 & $5 \mathrm{I}$ & 0.825 \\
\hline
\end{tabular}

Among other measurements on British G. z. zaddachi are the following. Ten specimens from the River Char at Charmouth, Dorset, all in the I35-I59 group, give a mean of 0.726 , conforming with the South Devon samples. A somewhat higher mean of 0.749 is given by a sample of 15 (of various sizes) from Appledore, North Devon. Too great stress is not laid on the exact values of the means, which may well vary a little in different areas: the significant fact is that an appreciable difference is maintained between $G$. z. zaddachi and G. z. salinus.

The contrast, however, may be appreciably less on the continent. From ten males of the fresh-water population of G. z. zaddachi (nine from Hamburg Wasserleitung and one from Bremerhaven), whose uropods were mounted by Mrs Sexton, the following results were obtained:

$\begin{array}{ccc}\text { Size group } & n & \text { Mean ratio } \\ \text { 160-199 } & 4 & 0.794 \\ \text { 135-159 } & 2 & 0.802 \\ \text { IIO-134 } & \text { I } & 0.76 \\ 96-109 & 3 & 0.758\end{array}$

I also observed that some of the specimens of G. z. zaddachi from Denmark (Copenhagen Mus. Coll., kindly lent by Dr K. Stephensen) appeared to have a longer inner ramus than is usual in British material. There is no evidence that salinus gives a comparably higher value.

\section{Urosome dorsal spines}

The pattern of the spine groups on the dorsal surface of the three urosome segments is usually given in descriptive works as a 'spine formula', in the form of the following example:

$$
\begin{aligned}
& 3: 2: 3 \\
& 3: 2: 3 \\
& 2: 2: 2
\end{aligned}
$$

where the top row represents the number of spines in the left, centre, and right groups of segment $\mathrm{I}$, the second row those of segment 2 , and the third of segment 3. The example given is that recognized as rather characteristic of $G$. zaddachi (e.g. Sexton, 1942, p. 600).

The above numbers are good central values for the species, but there is a marked variation in both directions for most of the groups. Even if full 
allowance is made for loss of spines through damage, there is frequently a difference between the numbers on the two sides of the body. As will be seen, the formula given above is virtually a minimum for $G$. z. salinus, and a maximum for G. z. zaddachi.

For G. z. zaddachi counts have been made on $8 \mathrm{I}$ males from the following localities: River Tavy, South Devon (8); River Plym, South Devon (47); River Char, Dorset (I0); River Severn (I6). The average values for the different groups tend to be similar in the four component samples, and there is no appreciable change with the size of the animal, so the total averages can be taken as representative. These are:

$$
\begin{aligned}
& 2 \cdot \text { I5 }: 2.0 I: 2 . \text { I5 } \\
& 2 \cdot 50: \text { I.99 }: 2.44 \\
& 2.05: I \cdot 98: 2.05
\end{aligned}
$$

The centre groups of all three segments and the lateral groups of segment 3 have nearly a constant number of 2 spines, quite rarely I or 3 . The lateral groups of segment I have usually 2, sometimes 3 ; and for segment 2 there are 2 or 3 about equally frequently: either may rarely have I or 4 .

The total number of spines ranges from $\mathrm{I}_{3}$ to $23,80 \%$ of individuals having I8 to 2 I. The mean value for the sample is $19 \cdot 4$.

By contrast, $G$. z. salinus shows a strong tendency to increased values, but individuals vary much. A sample of 20 from the River Avon, South Devon, gave the following averages:

$$
\begin{aligned}
& 3 \cdot I: 2 \cdot 3: 3 \cdot 15 \\
& 3.05: 2 \cdot I: 3.4 \\
& 2 \cdot 4: 2 \cdot 0: 2 \cdot 5
\end{aligned}
$$

Total spines: range $2 \mathrm{I}-28$, most frequently $22-25$; mean value $24 \cdot 0$.

One of 16 from the Severn Estuary gave:

$$
\begin{aligned}
& 3.23: 3.08: 3.23 \\
& 3.38: 2.38: 3.62 \\
& 2.69: 2.00: 2.62
\end{aligned}
$$

Total spines: range $20-34$, most frequently $23-28$; mean value $26 \cdot 3$.

The Severn population has the spines noticeably well developed, and the averages are probably higher than usual. The Avon sample appears to be more typical of salinus as a whole, judging from notes which have been made on other samples.

In salinus the central groups are usually not uniformly $2-2-2$, as in the typical form, a constant value of 2 being found only for the third segment. The second segment centre group, though most often 2 , is sometimes 3 ; while the anterior group is more frequently 3 and may be as high as 5. The lateral groups show a still greater average difference: segment I has most often 3 , sometimes 4 , 
rarely 2 or 5 (as against usually 2, sometimes 3); segment 2 has much the same, except 4 is more frequent (as against 2 or 3 equally frequent); segment 3 values of 2 and 3 about equally frequent (as against a nearly constant value of 2). The total number of spines ranges between 20 and 34 (compared with I3-23), but relatively low values, such as 22 and 24 , are common. The mean of 24 compares with $19 \cdot 4$ in G. $z$. zaddachi.

This character difference appears to be shown equally in both sexes, and to hold for both British and continental material.

\section{Presence of calceoli in the female}

The peculiar organs known as calceoli, which occur on the more proximal segments of antenna 2 flagellum (see, for example, Sexton, 1942, p. 598, and pl. i, figs. 2, 3), are present in many Gammarus males. For example, they occur in the males of G. locusta, G. sp. (northern 'locusta'), G. setosus, G. wilkitzkii, G. zaddachi, G. duebeni and G. pulex; but they are absent in G. tigrinus and $G$. cherreuxi. The presence of calceoli seems usually to be a male characteristic; though Sexton has not regarded it as such in G. zaddachi, and recently the writer has observed calceoli in females of G. setosus and G. wilkitzkii (probably a constant feature in these two species).

The position in G. zaddachi proves to be unusual, for calceoli may or may not be present in the female. The organs are, indeed, often developed in females of G. zaddachi salinus, though they may not begin to appear until after maturity; and they may be completely lacking, even in the largest and oldest individuals. On the other hand, in G. z. zaddachi, no females bearing calceoli have so far been observed. While this feature seems to merit further investigation, it is probably safe to say that there is a significant difference between the two subspecies in the tendency for the females to bear calceoli.

\section{Habitat}

The rather pronounced difference in the optimum environment and limits of range can be expressed quite satisfactorily in terms of salinity. Detailed discussion is deferred until the full ecological data have been presented. To summarize briefly, G. z. salinus, in Britain, inhabits brackish waters of various intermediate salinities with a general mean value of about $17 \%$. The middle reaches of estuaries which do not show too steep a salinity gradient provide habitats where the densest British populations have been found. It is here that the greatest range of salinity fluctuation in the estuary occurs, both diurnal, between high and low water, and periodic, between spring and neap tides; and it is here that the variety of the fauna is at a minimum. But daily fluctuation on its own is not an essential factor, as may be witnessed by the 
flourishing population towards the mouth of the River Severn. In Britain it is difficult to find brackish lagoons comparable with, for example, Frisches Haff, in Danzig Bay, and no British populations from a habitat of this kind have been observed. The limits of range have therefore to be defined in terms of estuarine conditions.

At the seaward limit of its range it persists so long as there is an appreciable lowering of salinity at high water. It seems not to tolerate a mean high-water salinity of more than $3 \mathrm{I}^{\circ} \%$, even though the low-water value is much less. At the other end, it disappears when there is too much fresh-water influence at low water, that is when the mean low-water salinity is between I and $4 \%$.

G. z. zaddachi has an optimum where the low-water salinity is quite fresh or below $\mathrm{I}^{\circ} \%$, but where a marked rise of salinity occurs at high water. Its estuarine limit is roughly defined by a mean low-water salinity of $5 \%$, with a mean high-water salinity of 10 to $15 \%$. At the river end, it may penetrate for several hundred yards, or even miles, into permanent fresh water, but here, in most British rivers and streams, it fails to reproduce. On the other hand, in some areas (e.g. north Irish lakes, River Elbe) it is capable of breeding and flourishing in pure fresh-water environments. The species as a whole shows a marked preference for waters with good currents, and is clearly not so tolerant of stagnant water as is G. chevreuxi and G. duebeni.

The localities which provide conditions suitable for G. z. salinus (in Britain very largely limited to estuaries of rivers) are less numerous than for G. $z$. zaddachi. Nearly every river (and most streams flowing on to the shore) provides, at the head of its estuary (or near high-water mark at its inflow), a region in which $G$. z. zaddachi can exist. On the other hand, in the tidal zone of streams, or in the estuaries of some rivers, the mean salinity gradient may be too steep to provide living space for salinus. Under these conditions population samples show $G$. locusta giving place to $G$. z. zaddachi with a narrow zone of overlap in which the Gammarus population is sparse.

\section{Constancy of character differences}

The separation of the two subspecies, as described above, is justified on morphological grounds alone, since individuals can always be placed in one or other category. It is important, however, to be able to present confirmatory evidence from experimental data. This can be done. Laboratory observations will be described in necessary detail in a later section of this work, but some main results may be summarized at this stage. In one set of experiments, the effect has been tested of rearing $G$. z. zaddachi in salinities higher than those of its normal habitat, e.g. I4, I7.5, $24 \%$ oo, etc. If any of the character differences found between G. $z$. salinus and the typical subspecies are simply the direct effect of differences in the environment, it is in salinity differences that the major effects can only be sought, as indeed Sexton has strongly suggested. Even the mere difference between the equable laboratory environment and 
the fluctuating conditions of the natural habitat might alter characters. The results so far obtained show complete absence of such effects. The $F_{1}$ generation retains the same degree of hairiness, etc., possessed by its parents, even when reared at $24 \%$ salinity. Even an $F_{2}$ animal, reared to late immaturity in pure sea water, as were its parents, was found to retain characters diagnostic of its type. These results are consistent with the field observations that the two forms retain their type characters in the zone where their populations overlap; and that within the range of each of them there is no evident gradation of lesser variations from the fresher to the salter end. It is also noteworthy that G. z. salinus from the Baltic coast of Germany, living at more or less constant salinities of $7-8 \%$, or less, shares the same type characters as those from British estuaries with salinity fluctuating around $17 \%$, and laboratoryreared animals kept at a constant salinity of $27 \%$. It is clear that phenotypic variation due to salinity differences can at best be of very limited extent. Results obtained by Höfken (1937) with G. zaddachi from the West Baltic had already pointed to this conclusion.

\section{Intersterility}

A further, and most significant, piece of experimental evidence comes from breeding experiments which were at first designed to test the genetic relations of the two types by crossing. Results obtained in I938 have been amply confirmed by a more extensive and detailed experiment carried out in I946. It is conclusively shown that, under conditions in which both subspecies breed freely and normally (e.g. in $14 \%$ salinity in bowls), they are incapable of producing fertile eggs with one another, whichever way the cross is made. They also mate (i.e. form pairs) less readily with each other than with their own kind. This (a) shows that there is important genetic difference between the two types, to which their character differences must be attributed, at least in some measure; (b) explains completely how it comes about that the populations remain distinguishable in nature even in the zone where individuals of both mix freely.

The question immediately arises whether sterility may not be prevalent among different populations of the same subspecies, in view particularly of the isolation which occurs between populations of neighbouring watersheds. So far as present information goes, there is no evidence for this, though tests with animals from widely separated areas have yet to be made. For instance, G. z. salinus from the River Avon, South Devon, breed normally with those from the River Tamar. G. z. zaddachi from Weymouth, Dorset, proved fertile with others from the River Erme and River Yealm, South Devon; while others of this subspecies from several South Devon localities have been bred together.

Genotypic versus phenotypic variation

The results obtained up to now in the study of variation in Gammarus $z a d d a c h i$ thus contain an element of surprise. From the evidence brought forward in existing literature, it was at least to be expected that evidence of 
environmental variation would be quickly forthcoming, and that no taxonomic division of the species would prove possible. Yet positive proof has been found for genetical differentiation, in that there are (at least) two main intersterile subdivisions of the species; whereas no positive evidence for phenotypic differentiation can yet be given.

It seems that more attention must be given to the possibility of different genetic types within the species, and that where differences are found in the characters of two populations these are not necessarily, or even probably, phenotypic, even if they show correlation with some definable environmental factor. In Britain two main well-differentiated genetic types have been demonstrated. Elsewhere there may be more than two of such 'major types', equally incapable of crossing with the typical subspecies and with salinus. If another such form exists, there is little chance that it would be absolutely distinguishable morphologically, and much closer statistical study might be necessary to recognize it. If it happened to bridge the gap between G. z. zaddachi and salinus an impression of continuous variation might be obtained; or if it closely overlapped one of them, it might escape detection until tested by breeding.

It would be useless to try completely to reconcile the picture presented by Sexton with the present viewpoint, until the former is supported by the necessary experimental observations. However, it is scarcely reasonable to suppose that conditions in the River Elbe, for example, are essentially different from those in British rivers. It has yet to be proved, that, if re-examined in the light of the character differences which hold good for British populations, two major types cannot equally well be separated in Germany, even if the variation within each is somewhat greater. The mystery of the 'intermediates' Sexton records is largely resolved by the discovery that these include $G$. $z$. zaddachi with somewhat less dense hairs than in the Hamburg 'fresh-water' population, especially on antenna I flagellum, but which characterize the bulk of the G. z. zaddachi population of south-west England. ${ }^{1}$ Until proved to the contrary it can only be assumed that the 'fresh-water' form plus most of the 'intermediates' of Sexton fall within the typical subspecies, while the 'brackish water' form includes salinus.

The alternative possibility that the salinus types completely intergrade with the typical form towards the more eastern part of the species' range, whereas westwards, in Britain, they have become quite separate and genetically isolated, provides an attractive solution to the problem. Though improbable, this may yet be partially true and would not be without parallel among other animals. But this conclusion would be of too great theoretical interest to be accepted so long as the crucial experimental data for the continental populations is lacking.

1 According to Mrs Sexton, who has recently been kind enough to look over some of my material, a large proportion of British G. z. zaddachi would be classed, in her original terminology, as 'fresh-water intermediates', a few as the 'fresh-water' form, or very nearly so, and others as grading between the two. 


\section{Taxonomic status}

The two major genetic types into which $G$. zaddachi has been divided (without prejudice to the fact that others may exist or even that further subdivision may be necessary), behave, for all practical purposes, as two distinct species. Ecologically they can profitably be treated as such. The reasons for not giving them specific rank are briefly as follows:

(I) Though separable on good visible differences in the development of spines and hairs, supported by average differences in various other respects, the two forms are identical, or very closely similar, in structures which normally show diagnostic specific characters, particularly the gnathopods, coxal plates, relative size of antennal segments, etc. Also both have the diagnostic pattern of hair tufts associated with G. zaddachi. Taxonomically, therefore, they are closer than other species of the genus are to each other. If they were made separate species, a dangerous precedent might be set for wholesale splitting in other species.

(2) Some uncertainty still remains on the relation between the salinus and typical forms in the eastern part of the range of zaddachi. Until this matter is clearer, it is advisable to proceed cautiously. $\dagger$

\section{Separation from related species}

G. z. salinus has been liable to confusion with G. locusta (sens.str.), with which it mixes near the mouths of estuaries. They are very easily separated in mixed samples, however, by the longer accessory flagellum of locusta, its relatively short segments $2+3$ of antenna I peduncle, which has very sparse hairs, the more spreading and less graded hair-tufts of antenna 2 , the more greatly elevated urosome segments, the deeper and more rectangular ventral half of coxal plate 4 , the long uropod 3 inner ramus, etc. In adult males the diagnostic gnathopod 2 hands are alone sufficient. In adult females the hand of gnathopod 2 of locusta is notably elongate, easily more than twice as long as broad (except in the youngest individuals), whereas in zaddachi it is easily less than twice. Immatures of all sizes can be readily separated, if examined when freshly killed, by the presence of reddish pigment spots on the peraeon segments of locusta (absent in zaddachi); otherwise the more numerous hairs on antenna I peduncle ventrally in zaddachi become evident at least by the time the immature are half-grown.

G. z. zaddachi is further distinguished from locusta by the abundance of hairs on the hinder parts of the body (though the hairs on the distal segments of peraeopod 7 are usually longer and more numerous in locusta than in G. z. salinus). The habitats, however, are usually well separated.

It is, however, to G. duebeni that G. z. zaddachi bears the closest superficial resemblance, as older determinations often bear witness. Their habitats are

$\dagger$ This uncertainty has been largely removed by Segerstråle (pp. 236-40), who, all the same, independently decided that zaddachi should not be split into separate species. 
liable to overlap, and mixed populations are collected in some localities. Adult males are at once separable on the form of the gnathopods: in duebeni the hand of gnathopod 2 is scarcely longer than that of gnathopod I, while the median palmar spine and the angle spines of gnathopod 2 form a continuous
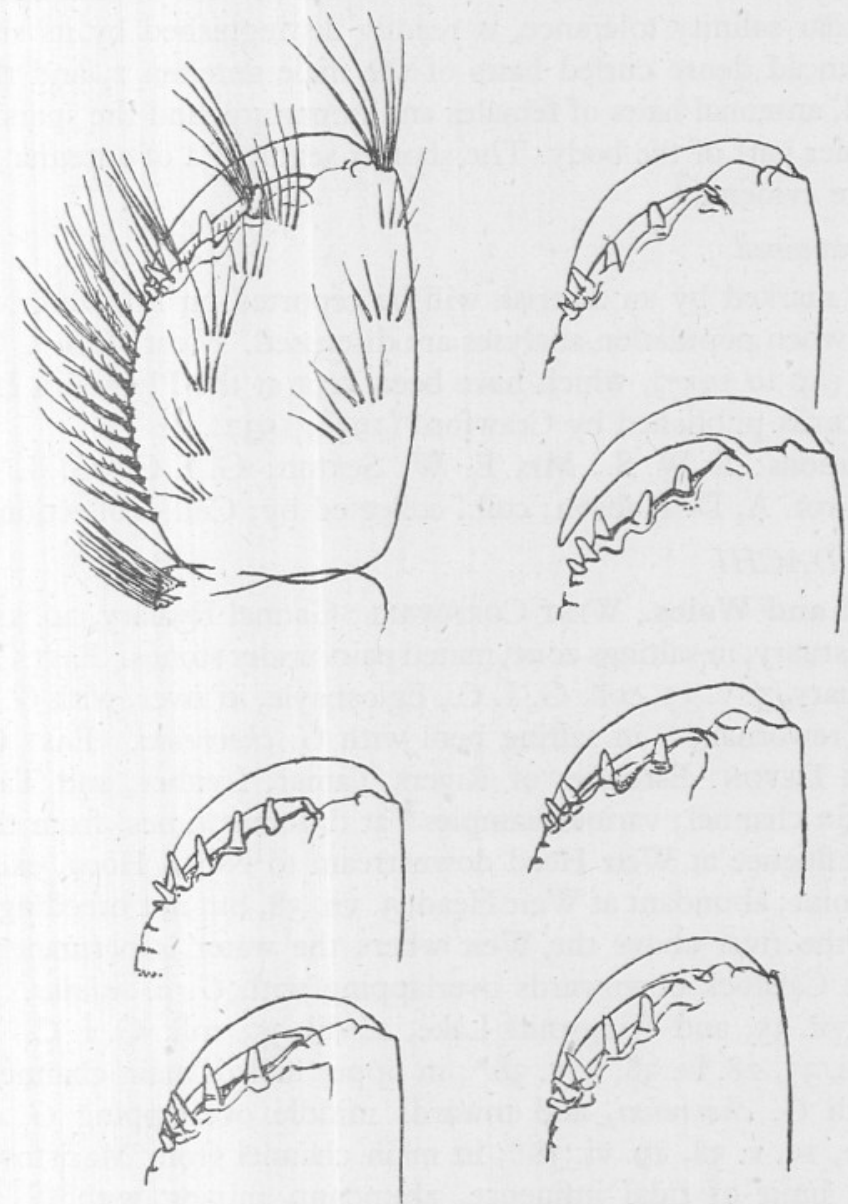

Fig. 7. Gammarus duebeni, from Chelson ditches, near Plymouth, male gnathopod 2 hand. One figured complete, and the distal part of six others with setae omitted, to show the arrangement and form of the palmar spines.

row (Fig. 7). All sizes of duebeni, particularly the immature and younger adults, are separable at once by the shape of the basal segment of peraeopods 6 and 7 -the posterior distal angle protruding and lacking spines, though this feature tends to be less evident in larger adults. In duebeni, moreover, the setation of antenna I peduncle is sparser, that of antenna 2 more concentrated in brush-like tufts; coxal plate 4 has a more rounded and U-shaped ventral 
expansion; the angles of the epimera are more nearly right angles; and the whole body is distinctly less slender. Immatures can be satisfactorily distinguished, to the smallest sizes, on the strength of the produced distal angle of peraeopod 7 basal segment.

G. chevreuxi, which is liable to occur in company with G. z. zaddachi, having a very similar salinity tolerance, is readily distinguished by its smaller size, the pronounced dense curled hairs of the male antenna 2, and the sparser, less graded, antennal hairs of females and immature, and the sparsity of hairs on the hinder part of the body. The shorter segment 2 of antenna I peduncle is also quite evident.

\section{Material examined}

Samples marked by an asterisk will be reported on in greater detail subsequently, when population analyses are discussed. Most of G. I. Crawford's collections (up to I937), which have been kept at the Plymouth Laboratory, refer to records published by Crawford (I936, I937).

Abbreviations: E. W. S., Mrs E. W. Sexton; G. I. C., G. I. Crawford; A. D. H., Prof. A. D. Hobson; coll., collected by; Coll., collection.

\section{G. Z. ZADDACHI}

England and Wales. West CoRnWall: Gannel Estuary, 20. xi. 37, creek at head of estuary, in saltings zone, mated pairs under stones. EAST CORNWALL: Camel Estuary, 5. v. 35, coll. G. I. C., Egloshayle, in river, with G. cherreuxi; 28. i. 40, Trewornan, + in salting pool with $G$. cherreuxi. EAST CoRnwall and South Devon: Estuaries of Rivers Tamar, Lynher, and Tavy. River Tamar, main channel; various samples ${ }^{\star}$ at different times, from the limit of estuarine influence at Weir Head downstream to North Hooe, exceptionally at Thorn Point; abundant at Weir Head, 3. vii. 38, but not breeding, and even present in the river above the Weir where the water is permanently fresh; from about Calstock downwards overlapping with G. z. salinus. Whitsame Creek, I2. vii. 35, and Kingsmill Lake, 2. viii. 35, coll. G. I. C. Tamerton Lake, 24 . xi. 37,28 . iv. 38,2 . v. $3^{8^{\star}}$; in upper half of main channel of creek, mixing with $G$. cherreuxi, and towards middle overlapping $G$. z. salinus. River Tavy, 19. v. 38 , 19. vi. $3^{8 \star}$; in main channel from Maristow Ford up to extreme limit of tidal influence, abundant, mixing with $G$. cherreuxi; Maristow and Lopwell areas, main channel and adjacent brackish creeks, 3. vii. 35, coll. G. I. C. River Tavy, Gnatham, I937, E. W. S. Coll., some large adults in a pool at about extreme H.w. level; Gnatham Creek, 28. vii. $3^{\star}$, in stream flowing into tidal zone of estuary, mixing with $G$. cherreuxi in tidal zone, and alone in fresh water above tidal influence. St John's Lake, at extreme upper end, in tributary stream by the road bridge, I8. xii. $37,5$. v. $3^{8}$, 28. iii. 40, I2. xi. $46^{\star}$, plentiful when adequate cover available, mixing with $G$. chevreuxi; sparingly further down channel in estuarine zone, meeting G. locusta. River Lynher: near St Germans, 25. vi. 38, coll. E. Percival, 
several, with two G. duebeni; Sheviock Wood, south end, I8. ii. 38, a number in stomach of a sea-trout, coll. P. H. T. Hartley. South Devon: River Plym: in main channel at upper end of estuary, 2. vi. 38 , I. viii. $3^{8^{\star}}$, from extreme upper part of Laira Lake to the river above Marsh Mills, numerous, though water milky with China Clay, mixing with $G$. chevreuxi and overlapping G. z. salinus. River Yealm, Cofflete Creek, at head of creek near Spriddlestone, I9. xi. 37,3 . vi. $46^{\star}$, plentiful, penetrating into fresh water and mixing with G. pulex. River Erme, I. i. 38 , I8. ii. $39^{\star}$, in main channel opposite Holbeton and in three stations down the estuary, overlapping $G . z$. salinus; also in brackish ditch behind an embankment. River Avon, I6. v. 38, I4. vi. 38, 8. i. 39 , I4. v. $46^{\star}$, in main channel from about half a mile below Aveton Gifford up to near limit of estuarine influence, abundant, overlapping G. z. salinus. Kingsbridge Estuary, Blank's Mill Creek, 22. i. $39^{\star}$, in three stations, overlapping $G$. z. salinus in middle of creek, and $G$. pulex in fresh water of stream above tidal influence. Dawlish, 2I. vii. 35, coll. G. I. C., in Copenhagen Mus. Coll., a number of dwarfed adults, breeding. River Exe: 'Exeter', R. Elmhirst Coll., 6 ธิธิ and I o; Countess Weir, 2I. vii. 35, coll. G. I. C., several in main stream, $3 \hat{\sigma}$ in tidal ditch; Powderham, brackish pond, 2I. vii. 35 , coll. G. I. C., numerous, mixing with G. duebeni; Topsham, tidal zone of estuary, $24 . x .3^{8^{\star}}$, several adults, overlapping $G$. locusta (G. z. salinus absent). River Axe, 21. xi. $3^{8 *}$, in main channel above Axmouth, overlapping G. z. salinus. NORTh Devon: Torridge Estuary, I4. iii. 38 , in brackish ditch near Appledore, large sample. Taw Estuary, Caen River, coll. G. I. C., 3 specs. DORSET: River Char, 2I. xi. $3^{8 *}$, in river just above its fall over the beach, large adults. The Fleet, 27. iii. 38 , in brackish ditch near Langton Herring. River Wey and Radipole Lake, 2-IO. ix. $38^{\star}$, in several stations, plentiful, though of small average size, in open water and in ditches, crowding amongst tubes of Mercierella enigmatica and at roots of Phragmites. Lodmoor, Weymouth, ditches near sea sluice, iv. 28, sample of large adults, 26. xii. 37, I4. xi. 37, sparingly. Hants: River Test, Totton Br., 7. xii. 35, coll. G. I. C., in British Mus. Coll. [1936. 2. 12.95-99]. SEVERN EstuARY: In various samples from the upper reaches of the main estuary, coll. R. Bassindale, as reported in the 'Studies on the Biology of the Bristol Channel' series, nos. IV, VII, VIII and XI (Bassindale, I94I, I942 $a$, I942 $b$, I943), recorded as 'zaddachi, typical variety, Spooner (in lit.)', corrected to 'Form C Sexton'; 1 in main channel and tidal zone of estuary from Aust (summer) or Sharpness (winter) to Ashleworth Ferry, also at Kilve where a tributary fresh-water stream flows over the tidal zone; overlapping G. z. salinus at Sharpness (summer) and from Aust to Sharpness (winter), while above Epney showing

\footnotetext{
1 The correction in Bassindale ( $1942 b, \mathrm{p} .3 \mathrm{I} 4$ ), which was added when the writer was away on war service, is now seen to have been superfluous. 'Typical variety' was the provisional name given to G. z. zaddachi; and 'saline variety' to G. z. salinus, which in the Severn can be incompletely divided into two forms, A and B (see p. 42). The statement that intermediate forms occur between Forms A and C (i.e. between the two subspecies) was incorrect.
} 
signs of inhibited growth and development, especially in winter. Essex: Benfleet, 8. iii. 36, in two places, coll. G. I. C. [British Mus. Coll., 1938. 2. I6. 52-59]. Leigh-on-Sea, 28. vi. 36, coll. G. I. C. [British Mus. Coll., do.]. Norfolk: Stiffkey, 29. ix. 35, coll. G. I. C. [British Mus. Coll., I936. 2. I2. 95-99]. DURHAM and NorTH-EAST Yorks: River Tees, Tees Survey collections (Alexander et al., I935), various samples from sections I, II, III, IV and VIII, in main channel or tidal zone. See pp. 46, 5I. CARMARTHENSHIRE: River Towy, 25. viii. 35, coll. G. I. C., 'open stream through salting among

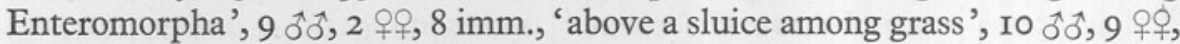
I $5 \mathrm{imm}$. MERIONETHSHIRE: Aberdovey, at head of estuary, coll. E. E. Watkin, several $0 \hat{0}$. ANGLESEY: Lake Maltreath, brackish water, 27. iii. 40, coll. J. B. Cragg, 6 ิํ, I i. IsLe of MAN: Castletown, Silver Burn, 7. ix. 38, coll. G. I. C., near mouth of fresh-water stream, flowing into the sea, in three stations, dwarfed. Westmorland: River Gilpin, Sampool Br., I6.v. 38, coll. P. H. T. Hartley, 7 कै $\sigma^{\circ}, 6$ 워, I2 imm., average size small.

Scotland. FIRTH OF TAY: River Tay, Tees Survey collections (Alexander et al., I935), identified from sections I, II, III, IV, VI, VIII, IX, X (see pp. $47-8,52)$, small-sized from higher sections where salinity very low or mainly fresh water, in the two lowest Sections overlapping G. z. salinus. AYRSHIRE: Fairlie Sands, 7. vi. 40, coll. R. Elmhirst, in stream flowing into tidal zone of shore, overlapping G. duebeni at the fresh-water end, and G. z. salinus at the seaward end of its range (see Scottish Marine Biol. Assoc., Annual Report, I942-3, pp. II-I2). ARGYLLSHIRE: Oban district, coll. H. P. Moon: Gylen Castle, I. viii. 39, 'stream flowing over beach, just above Enteromorpha zone', 9 imm., with G. duebeni; Slatroch Bay, 12. viii. 39, 'stream across shore, about middle of bay, amongst Enteromorpha, associated with ephemerid Baetis',

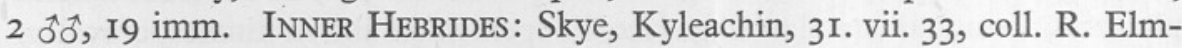

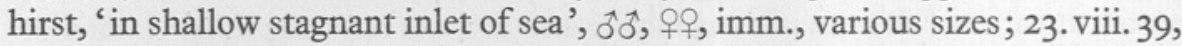
coll. H. P. Moon, 'point where stream flows over beach, and into Enteromorpha zone', 7 imm., in both samples mixed with $G$. duebeni. Isle of Muck, Port Mor, A. D. H. Coll., in fresh-water stream on shore, 29. vii. 38, $3 \hat{\jmath} \hat{\sigma}^{2}, \mathrm{I} \mathrm{imm}$. South Rona, vii and viii. 37, A. D. H. Coll., in three streams flowing over the shore, in tidal zone but not above mean H.w. (see Beadle \& Cragg, I940, as zaddachi 'hairy' variety), mostly small sizes. Raasay, viii. 37, A. D. H. Coll., in stream flowing over shore, above H.W., small $q$ and imm.; Oskaig Salt

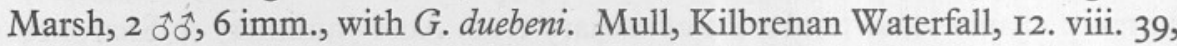
coll. H. P. Moon, 'tidal pool at foot of waterfall, Pelvetia zone', 2 young $\widehat{0} \widehat{0}$, $23 \mathrm{imm}$.; Enteromorpha zone, I young $\hat{o}, 3 \mathrm{imm}$. Outer HeBrides: South Uist, I. viii. 32, R. Elmhirst Coll., Loch Bee, several, mostly males, not fully mature and dwarfed. North Uist, R. Elmhirst Coll., I8. vii. 33, Loch Obisary, brackish, several small-sized adults; 24. vii. 33, Sollas, stream from Loch Sandary, I imm.; 28. vii. 33, Loch an Sticar, adults and imm. Harris, near Tarbert, coll. H. P. Moon, 22. viii. 39, Glen Lingadale Burn, Enteromorpha 
zone, Io ડึరิ, 3 우우 (breeding), 3 imm.; 20. viii. 39, Laxadale River, Entero-

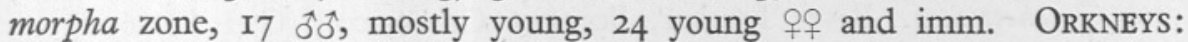
R. Elmhirst Coll., 'W. of Douglas Hill, upstream, amongst green alga and stonefly larvae, fresh water', 8 imm., including 2 developing 0 characters.

Ireland. SOUTH KERRY: Kenmare, 23. vii. 38, coll. G. I. C., small brackish stream, 2 ธิธิ, I + (with one G. z. salinus). Glenbehy, 2I. vii. 38, coll. G. I. C., brackish ditch, among Fucus, $6 \widehat{0} \sigma^{\hat{\alpha}}$, I imm., in Enteromorpha, a number of smaller sizes (with G. duebeni). Dublin: River Liffey, at Kingsbridge, I7. vii. 38 , coll. G. I. C., just below limit of tidal influence, $5 \hat{\jmath} \hat{\jmath}, 16$ 우 imm. (with G. duebeni). County Down: The Kinnegar, Holywood, coll.

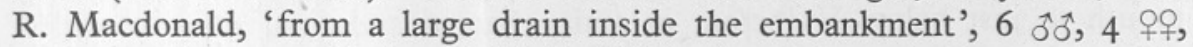

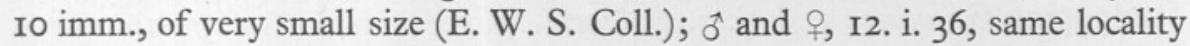
and captor (Copenhagen Mus. Coll.).

Belgium. Schelde Estuary, below Antwerp: Lillo, 'stream along road from Stabroeck', I 5. v. 36, 4 ơ ơં; Liefkenshoeck, I5. v. 36, 4 ơ ô, 9 우우, 2 imm.; Copenhagen Mus. Coll. (ex Brussels Mus. Coll.).

Germany. RIVER ELBE: Hamburg Wasserleitung (conduits connected with former water supply), E. W. S. Coll., series of mounted parts of three males, and mounts of uropod 3 of six others, typical 'fresh-water' form, teste E. W. S. RIVER WESER: Bremerhaven, I2. v. 94, E. W. S. Coll., series of mounted parts of large ô, 'fresh-water' form; I0. xi. I2, R. Elmhirst Coll. (ex E. W. S. Coll.), large $\widehat{\jmath}$. (Examples of original material described by Sexton, I9I2, I942.) Prussia: Swinemünde, 5 ờ ${ }^{2}$, Copenhagen Mus. Coll. (from Prof. A. Schellenberg, Zool. Mus. Berlin), 'Gammarus locusta f. zaddachi, typische form: A. Schellenberg det.' E. Prussia: Danzig, Messina See, brackish water, $\widehat{t}$ and $q$, Copenhagen Mus. Coll. (R. Lucks, Marienburg, col. et ded.).

Denmark. Samples from Copenhagen Mus. Coll. West Jutland: Aagab (Holmsland), Ringköbing Fjord, coll. K. O. Leith, 7. vii. 42, one smallish ô. Vondaa, between Heager and Kloster, coll. K. O. Leith, 27. vii. 42, 8 ธิธิ 7 웅, 2 imm., breeding, abnormally dwarfed. South-wEST JuTLAND: Maade, $3 \mathrm{~km}$. east of Esbjerg, 24. iv. 43, coll. E. Pedersen and K. O. Leith, o and imm. NoRTH-EAST JutLAND: Randersfjord, Uggelhuse, near Bridden Thor, I9. v. I7, I imm. North-west Zealand: Lammefjordssöen, to 3 m., 3. v. 23, I (Dansk. Biol. Sta. ded.).

\section{G. Z. SALINUS}

England and Wales. EAST CoRnwall and South Devon: Estuary of River Tamar, and its tributaries River Lynher and River Tavy. River Tamar, main channel, various samples from Saltash upwards to Calstock, overlapping $G$. locusta from Saltash to Cargreen (winter) or from Junction of Tavy to above Weirquay (summer), and at the upper end of its range overlapping G. z. zaddachi from near Weirquay upwards (winter) or from near North Hooe upwards (summer); absent from St John's Lake. Tamerton Lake, 
28. iv. 38,2 . v. $3^{8}$, in main channel, overlapping G. locusta, G. z. zaddachi and G. cherreuxi. River Lynher, Sconner Creek, coll. G. I. C., 6. vi. 35, young 0 and imm. River Tavy, I9. v. 38, 28. vii. 38, from junction with the Tamar to Maristow Ford, in open part of estuary, overlapping G. locusta and G. z. zaddachi. South Devon: River Plym, 2 and 28. vi. 38, I7. i. 46, in main channel and tidal zone, from near south end of Laira Lake to below Marsh Mills road bridge, plentiful, overlapping G. locusta, G. z. zaddachi and G. chevreuxi; Chelson Sluice, 23. xi. 45, 2 우. River Yealm, in estuary near Steerpoint station, iv. 40, overlapping $G$. locusta (apparently absent Cofflete Creek). River Erme, I. i. 38, I8. ii. 39, 5. iii. 39, from near estuary mouth to just below Holbeton, in main channel and tidal zone, plentiful, overlapping G. locusta and G. z. zaddachi. River Avon, I6. v. 38, I6. vi. 38, 8. i. 39, I4. v. 46 , in main channel and tidal zone from near Bantham to a little below Aveton Gifford, abundant, especially in clusters of fucoid algae, as usual overlapping $G$. locusta in one direction and G. z. zaddachi in the other, with a long stretch of 'pure' population in the middle of its range. Kingsbridge Estuary, Blank's Mill creek, 22. i. 39, in channel and tidal zone. River Axe, 21. xi. 38, above Axmouth, overlapping G. z. zaddachi. Dorset: River Frome, Wareham, coll. G. I. C., 2. ix. 35, 2 imm. SEvern Estuary: In various samples from Bristol Channel coast and Severn Estuary, coll. R. Bassindale (see references given on p. 39 and the attached footnote), from at least Blue Anchor (winter) and Kilve (summer) upwards to Sharpness; the population tending to be dimorphic, the recorded 'Variety A' agreeing with $G$. z. salinus from other estuaries, while the more abundant 'Variety B', distinguished by its small eyes, and its unusually long hairs and spines, has been observed only from this estuary; the two varieties not always completely separable, and occurring throughout the range of the subspecies; occurrences correctly reported in Bassindale (I94I); as elsewhere, overlapping G. $z$. locusta at the seaward end of its range (Blue Anchor to Weston) and G. $z$. $z a d d a c h i$ at the other end (Aust to Sharpness). LINCs: River Welland, near Holbeach, main dyke running into the river near Holbeach, 20. vii. 39, coll. M. L. Rothschild, 2 ธิธิ, $2 \mathrm{imm}$. NorthumberLand: Blyth, 'ditch from saltpans', 4. vii. 34, A. D. H. Coll., 3 우, breeding, with G. locusta. Wansbeck, 9. iv. 35, A. D. H. Coll., 'below railway bridge, among Fucus in stream', 9 ธิธิ, 10 웅, $3 \mathrm{imm}$.

Scotland. AYrSHIRE: Fairlie Sands, 7. vi. 40, coll. R. Elmhirst, in stream flowing over tidal zone of shore, overlapping G. z. zaddachi (see Scottish Marine Biol. Assoc., Annual Report, I942-3, pp. II-I2). Clyde Isles: Cumbrae, east of Keppel Pier, near Lion Rock, shore near L.w., I6. ii. 43, 2 large $\delta \hat{\sigma}$. ARgYllshire: Clachan Strand, 2. vi. 35, 'under weed', A. D. H. Coll., young $\hat{o}$ (with $G$. locusta and $M$. marinus).

Ireland. SOUTH KERRY: Kenmare, 23. vii. 38, coll. G. I. C., small brackish stream, I ô (with G. z. zaddachi). 
Germany. RIVER WeSER: Bremerhaven, Alter Hafen, Dec. I9I I, Herr Klie; E. W. S. Coll., series of mounted parts of young adult, figured by Sexton, I9I2, and a few immature specimens (types).

Denmark. South Zealand: Stege Nor, opposite Kirkegrund, 25. vii. 29, I young $\hat{o}$, Copenhagen Mus. Coll. (E. Poulsen ded.).

The following examples, originally identified with salinus, are separable on characters of the antenna I peduncle (Fig. $5 \mathrm{~F}$ ), and by the somewhat more angularly elevated urosome segments. Apart from their relatively small size, they approach very close to the northern $G$. 'locusta'. $\dagger$ Amongst them is a female specimen, from Raasay, which is unusually large for a British zaddachi $(2 \mathrm{I} \mathrm{mm}$.). Amongst characters shared with salinus are all those in which the latter differs from zaddachi typical. It is possible that the Cumbrae specimens recorded above should also be included in this category.

Scotland. Firth of TAY: Tees Survey collections (Alexander et al., 1935), in sections IX and $\mathrm{X}$ of the estuary (see pp. 48, 52). INNER HEBRIDES: South Rona, vii and viii. 37, A. D. H. Coll., in stream flowing over shore, well below H.w., ${ }^{t}$ and imm. (Beadle \& Cragg, 1940, as 'zaddachi, hairless var.'). Raasay, vii and viii. 37, A. D. H. Coll., in stream flowing over

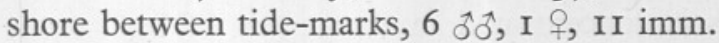

Germany. EAST PRUSSIA: Rauschen, Königsberg, series of mounted parts of adult $\hat{o}$ and + , E. W. S. Coll. (see Sexton, 1912, 1913).

\section{REVISION OF PUBLISHED IDENTIFICATIONS}

\section{Fauna of Tamar and Lynher (Percival, 1929)}

The faunistic survey of the Tamar estuary, and its branch the Lynher, carried out by Percival in I928, has been frequently quoted in comparisons with other estuaries. It is necessary that his statements concerning the Gammarus fauna (Percival, 1929, pp. 92-3, I03) should be corrected in the light of present knowledge.

A small reference collection was left by Percival in the Plymouth Laboratory. This, unfortunately, was unknown to Crawford (1936, 1937), and overlooked by Sexton (1942).

Percival did not submit his Gammarids to a specialist for confirmation. This might have seemed unnecessary, as at the time the choice of species apparently lay simply between $G$. locusta and $G$. duebeni. As a result G. zaddachi was completely overlooked, and G. chevreuxi (at the time known only from Chelson Meadows ditches) missed.

G. locusta. Though no specimens were preserved, it is quite clear, as Crawford suspected, that Percival included G. zaddachi salinus in this category.

† Both are now to be included in Segerstråle's third subspecies of zaddachi (pp. 223 et seq ). This form would appear to replace salinus in north Scotland, and so raises a new problem. 
The upper limit at Morwell Rocks is in fact rather higher than the point reached by salinus in June I938, but might well represent the extreme upper limit of that form in a dry summer. The true upper limits of locusta are found to be at the bend above Weirquay in an average summer, and at Cargreen in the winter. This applies to the region of low water: the species penetrates a little higher in the upper half of the tidal zone.

$G$. duebeni. This species is not a normal inhabitant of the main stream of the estuary, but is virtually confined to backwaters and side channels, e.g. pools near high-water level fed by fresh-water seepage, salting pools, ditches separated from the river by sluices, etc. The form recorded as 'duebeni' by Percival in the Tamar 'from Cothele Woods to Weir Head' is really G. z. $z a d d a c h i$. Its summer range is thus quite accurately described, and, as Percival noted, it swarms amongst moss at Weir Head. Similarly this is the form which frequents the Lynher 'from Sheviock Wood to Tideford', as is proved by a preserved sample, labelled ' $G$. duebeni, R. Lynher, near St Germans, 25. vi. 28'. This sample contained $8 \hat{\widehat{\jmath}}, 5$ 우 large $\delta$ and one small + $G$. duebeni.

No comment is necessary on the range of Marinogammarus marinus, there being good agreement with later observations. It should be emphasized that the population of this species is concentrated in the region of high-water neaps, and usually the species is quite absent from the low-water region, unless the gradient of the intertidal zone is steep.

Amongst other crustaceans in Percival's samples which have been examined are the following:

Sphaeroma serratum F. Wyvlescombe Lake, River Lynher, 22. viii. 28, confirmed correct.

Sphaeroma rugicauda Leach. River Tiddy and Marsh, 25. vi. 28. 5 ỡ 5 우우, confirmed correct.

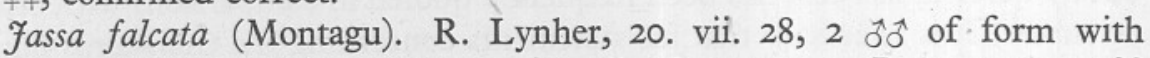
large gnathopod hands. Hamoaze, I9. vii. 28 , on no. I5 Buoy, 2 ธิธิ, 2 우 (recorded as Podocerus odontonyx Sars).

Cyathura carinata (Kröyer). As Crawford (1936, p. 37) rightly suspected, Percival's records for Anthura gracilis Montagu really refer to this species. Specimens from Rat Island, 30. viii. 28, were preserved.

\section{Collections by G. I. Crawford and others}

Subsequent to the discovery of $G$. zaddachi in Britain, estuarine collections of gammarids have been given deserved critical attention. Recent records from the south-west, published by Serventy (I935), Crawford (I936, I937), Milne (I940), Spooner and Moore (I940), require no further qualifications, except in one respect. In the various records of $G$. zaddachi distinction has to be drawn between the two subspecies.

Serventy (I935) first recorded the occurrence of the species in the Tamar, 
from collections made at Pentillie Quay, Whitsam, and at a point one mile below Calstock in March I934. Two tubes of Serventy's specimens have been examined: one labelled Pentillie Quay, and the other without locality label. Both contain G. z. salinus, the former 6 ô, 5 우 and 7 imm., the latter many of various sizes.

$\mathrm{Mr}$ G. I. Crawford added much to our knowledge of the distribution of Amphipoda in the west. Most of his preserved collections remain at the Plymouth Laboratory, and it has been possible to re-examine nearly all the G. zaddachi he records (Crawford, 1936, p. 102; 1937, pp. 650-60).

From Rivers Tavy, Tamar and Lynher (p. 650), the following records refer to $G$. z. salinus:

Rat Island, low water, 3I. v. 35, 2 imm. amongst G. locusta.

Neal (or Neille) Point, 2. viii. 35, on buoy, a number, mostly 우 and imm.

Crosspark Wood, 3. ix. 35, among Obelaria gelatinosa at low water, small of and imm.

Lynher, Sconner Creek, 6. vi. 35, west bank among Fucus, young ${ }_{0}^{1}$ and several imm.

The following refer to G. z. zaddachi:

St Budeaux, open creek. Kingsmill Lake, creek above sluice. Whitsam and Haye creeks. All samples from the River Tavy in the region of Blaxton, Mt Jessop and Lopwell, in main channel and creeks.

The G. zaddachi recorded from the upper estuarine zone of the River Exe (p.652), River Taw (p. 654), River Camel (p. 654) and River Towy (p. 655), are all G. z. zaddachi. The sample from a pond on the Powderham Estate, River Exe region, contained many $G$. duebeni mixed with the zaddachi. Two immatures from the River Frome at Wareham, Dorset (p. I02), are G. z. salinus.

In his investigation of the fauna of buoys in the seaward part of the Tamar estuary, Milne (1940) again found G. zaddachi present on Neal Point Buoy, and his specimens proved to be $G$. z. salinus.

\section{Tees Survey Material}

The first comprehensive survey of a British Estuary was carried out on the River Tees, supplemented by observations on the River Tay. The results were published in three parts (Water Pollution Research, Technical Papers, no. 2 , I931; no. 5 , 1935; no. 6, 1937). In the analysis of fauna of the estuarine zone in Part II (Alexander et al., 1935, p. 44 onwards), five species of Gammarus sens.lat. are recognized from the two rivers (p. 55). At the time of the survey, however, the status and distinguishing features of G. zaddachi were still not widely appreciated, and the species into which Marinogammarus marinus auctt. has recently been separated were still unknown. 
Fortunately representative samples of the fauna were deposited at the Plymouth Laboratory, and it has been possible to revise identifications and to make some important corrections. A list of the preserved samples is given in the Appendix.

\section{River Tees}

Gammarus pulex L. Penetration into section I of the estuary, at Yarm, is confirmed, in shore and shrimp-trawl collections. Here it mixes with the more abundant G. z. zaddachi (see below). Casual specimens may well occur further down the estuary in the plankton in winter, but the statement 'occasional in plankton down to [section] VII' should be taken with reserve, as two out of five samples labelled ' $G$. pulex' from other stations were, in fact, G. zaddachi.

G. zaddachi Sexton. This was entirely overlooked in the Tees. The typical subspecies, abundant in the upper half of the estuary, was wrongly attributed to $G$. duebeni (sometimes to $G$. pulex). All statements under the heading of 'duebeni', as affecting the River Tees, should be transferred to G. z. zaddachi. Samples have been confirmed from the following sections: I, overlapping G. pulex, but more numerous; II and III, where evidently abundant, and the only species; IV, in the tidal zone under Fucus, where occurred a mixed population of this and duebeni; and in several tow-nettings. Another sample, labelled ' $G$. duebeni', proved to be exclusively G. z. zaddachi. Unfortunately no samples survive from the main stream or low-water region of sections IV-VII, but it may be assumed that all the ' $G$. duebeni' recorded from here are the typical subspecies of zaddachi. Had G. zaddachi salinus occurred in this region, it would presumably have been recorded as ' $G$. locusta', as in the Tay. No evidence can be found for the existence of salinus anywhere in the Tees, and it is significant that the centre of its expected range coincides with the polluted zone between Stockton and Middlesbrough, where a wide-and quite abnormal-gap occurred in the Gammarus population.

G. duebeni Lillj. This species may be expected to occur sporadically in the tidal zone where fresh-water streams or seepage make permanent pools of more or less brackish consistency. It has been confirmed only from the tidal region in section IV, where a number were taken under Fucus vesiculosus in company with the preceding species.

G. locusta (L.). The range as given, sections XIII and XII intertidally, and in tow-nettings up to IX, is probably entirely correct, as these zones fall well within the anticipated range (up to IX or X in summer and X or XI in winter). One sample tube labelled ' $G$. locusta' contains this species only. There are also several in a sample of mixed amphipods from section XIII; and others in tow-nettings labelled 'T 2 I B', 'T 23 ' and ' $\mathrm{T} 25$ '.

Marinogammarus marinus (Leach). There is no opportunity of confirming the species of this genus, except for some true marinus from section XIII. 
However, the reported distribution of marinus from XIII to X intertidally may be taken as correct. The bottom records for XIII to XI and in S XII are more likely to refer to $M$. finmarchicus Dahl (see below).

It will subsequently be shown that the revised picture of distribution of the different species conforms with results obtained from other British estuaries, though the Tees presents one outstanding peculiarity which clearly demands a special explanation. This is the complete break in the continuity of the Gammarus population between sections VII and X. In a normal river this gap would be bridged by a slight upward extension of $G$. locusta and by the dominant presence of $G$. zaddachi salinus, which appears to be completely absent. (The last, if present, should overlap G. z. zaddachi about up to section VI.) M. marinus should occur intertidally at least to section VII. The argument that the poverty of the fauna in this region of the Tees is due to pollution, if otherwise unproved, would have been very strongly reinforced by this further analysis of the Gammarus populations.

This point is worth further emphasis. It is now established that Gammarus populations remain dense throughout the length of an estuary, and numbers are not affected by the rigorous conditions of the mid-estuary region which reduces the variety of animal forms to a minimum. This is possible because a succession of forms (species or subspecies), each adapted to a special salinity range, and each overlapping its neighbours, occupies the whole stretch from the fresh-water river to the sea. The only natural limiting factor which may effectively reduce numbers is absence of suitable cover. But almost any available cover is made use of, varying from growing weeds to decomposing rubbish, and is never so lacking as to eliminate gammarids altogether. In the middle region of the Tees there is evidently, from accounts, sufficient cover to support a population of Gammarus, and absence of the latter indicates some effective polluting agency. Furthermore, since gammarids are not eliminated by contamination of waters with sewage or rubbish, it could be concluded that industrial effluents containing a significant concentration of some toxin was causing pollution. Poisoning was in fact found to be due to cyanides.

\section{River Tay}

G. pulex. Amongst material which Mrs Sexton has kindly shown me is a pair of G. pulex from the River Tay near Elcho, 2I. i. 32. This locality is near the limit of tidal influence in the main river, but well away from the influence of brackish water. So far as we know the species is uncommon in the soft waters of Scottish rivers. It is not recorded in the Survey Report from the River Earn, which was chosen for following the conditions at the very upper limit of tidal influence.

G. zaddachi. This species was correctly recognized in some samples, but only the typical subspecies in the upper part of its range. G. z. zaddachi was correctly recorded from the bottom and tidal zones of sections. I-IV. But it 
occurs equally in samples from various other sections down to X. Here again there was confusion with $G$. duebeni, but the latter species occurred intertidally with greater frequency than is usual (see below). In the upper part of its extensive range in the Tay, i.e. in sections I-IV, or Bridge of Earn to Newburgh, it was colonizing fresh water or water rarely greatly raised in salinity. This tendency is now known to be a usual feature. Characteristically too, the animals from these sections are of a small size and appear to show inhibited development: they were probably not reproducing.

In sections IX and $\mathrm{X}$, in which $G . z$. zaddachi was becoming scarcer, examples of a 'saline' or 'non-hairy' form of G. zaddachi occur.† These had presumably been recorded as G. locusta, since none of the latter was found in samples higher than section XI, which represents indeed the predictable upper limit. The seaward limit of G. zaddachi in the Tay cannot be determined, through paucity of preserved specimens from XI, and their absence from XII and XIII.

G. duebeni Lillj. This species, as will be shown elsewhere, does not normally form a member of the estuarine succession, but occurs on the edge of the tidal zone and intertidally where special conditions exist-e.g. marked fresh-water seepage from the land. It appears, however, to have been genuinely more plentiful in the Tay estuary than is usual. Recorded as 'abundant between tidemarks from sections $\mathrm{V}-\mathrm{X}$ ', it has been confirmed in the following samples: $\mathrm{V}$ [tidal zone], a number of well-grown adults; VI, tidal zone, large sample in which G. z. zaddachi was mixed; VII, tidal zone, large sample in which G. z. zaddachi was nearly as plentiful; IX, high-water level, a number of adults (but none low-water level); X, mid-tide level, 39 well-grown adults. The record for the bottom in VI should be referred to G. z. zaddachi (four samples are entirely of this species).

G. locusta (L.). As pointed out above, the occurrence in sections IX and X should be referred to $G$. zaddachi. It genuinely occurs, however, in section XI, at least at near high-water level. Unfortunately the surviving samples from this zone are scanty, and there are none preserved from sections XII and XIII. The species, however, may be assumed to inhabit the seaward end of the estuary from XI onwards.

Marinogammarus marinus (Leach). The correct range was originally given, and the species appears to be normally plentiful in the upper part of the tidal zone, up the estuary to section VIII. It was also well distributed down to low water in sections IX-XI. In section XI, however, the next species was found mixed up with it.

M. finmarchicus (Dahl), a species unknown at the time of the survey, can be added to the fauna of the Tay Estuary, as already reported (Sexton \& Spooner, 1940). It was, indeed, in revising the Tay material that the writer

$\dagger$ Not the true G. z. salinus, but a form with a more sparsely-haired and shorter antenna I peduncle: see p. 43 . 
first recognized the occurrence of this distinct species in the British Isles, though it has proved easy to collect it below the Plymouth Laboratory. Normally marine intertidal, with the centre of its distribution in the lower half of the tidal zone, it does not appear to extend very far into estuaries, but a stony ground may be essential to it. In the Tay section XI appears to be its upper limit.

The revised picture of distributions again agrees in essential respects with those from estuaries in the south of England. It is incomplete at the lower end, but it would appear that the zone in which a 'saline' form of Gammarus zaddachi forms $100 \%$ (or nearly so) of the Gammarus population is quite narrow. But it is important to remember that the summer and winter distributions are not distinguished. Special features are provided by the unusual abundance of $G$. duebeni in the tidal zone, by the penetration of Marinogammarus finmarchicus up to, or even beyond, the limit of Gammarus locusta, and by the apparent replacement of $G$. z. salinus by a form more closely akin to the northern G. 'locusta' (see p. 43). The dominance of G. $z$. zaddachi for such a long stretch in the upper parts of the estuary is noteworthy, but quite in keeping with its habits elsewhere. It would be interesting to know how far it succeeds in reproducing above the level of Newburgh.

Certain difficulties encountered by Bassindale (I942a, p. 138 et seq.) in his attempt at comparing the zones occupied by different Gammarus spp. in several rivers, are now disposed of. ${ }^{1}$ In the Tay $G$. locusta appeared to penetrate further up river than usual, but this was only because the 'saline' form of $G$. zaddachi had been overlooked, and even in section XI of the river $G$. locusta has only been confirmed from the high-water zone. G. z. zaddachi had also been overlooked from sections $\mathrm{V}$ to $\mathrm{X}$, so that $G$. duebeni finds its proper place as a colonizer of the intertidal zone, and not as an interloper in the main locusta-zaddachi-pulex succession.

\section{REFERENCES}

Alexander, W. B., Southgate, B. A. \& Bassindale, R., I935. Survey of the River Tees. Part II. The estuary-chemical and biological. D.S.I.R. Water Pollution Research, Tech. Paper No. 5, H.M. Stationery Office.

Bassindale, R., I933. Abnormal eyes in wild Gammarus zaddachi Sexton. Fourn. Mar. Biol. Assoc., Vol. xIx, pp. 297-8.

- I94I. Studies on the biology of the Bristol Channel. IV. The invertebrate fauna of the southern shores of the Bristol Channel and Severn Estuary. Proc. Bristol Nat. Soc., Ser. iv, Vol. Ix, pp. I43-20I.

- I942a. Studies on the biology of the Bristol Channel. VII. The distribution of amphipods in the Severn Estuary and Bristol Channel. Fourn. Anim. Ecol., Vol. XI, pp. I3I-44.

- I $942 b$. Studies on the biology of the Bristol Channel. VIII. An account of collecting stations, and corrections to the fauna list. Proc. Bristol Nat. Soc., Ser. iv, Vol. IX, pp. 304-I5.

${ }_{1}$ Bassindale was mistaken in supposing that all the Tay identifications were correct. 
BASsIndale, R., I943. Studies on the biology of the Bristol Channel. XI. The physical environment and intertidal fauna of the southern shores of the Bristol Channel and Severn Estuary. Fourn. Ecol., Vol. xxxI, pp. I-28.

Beadle, L. C. \& Cragg, J. B., I940. The intertidal zone of two streams and the occurrence of Gammarus spp. on South Rona and Raasay (Inner Hebrides). Fourn. Anim. Ecol., Vol. Ix, pp. 289-95.

Chevreux, E. \& FAge, L., I925. Amphipodes. Faune de France, Vol. Ix, 488 pp. Paris.

Crawford, G. I., I936. Additions to the Plymouth Marine Fauna (I93I) in the crustacean orders Tanaidacea, Isopoda and Amphipoda. Fourn. Mar. Biol. Assoc., Vol. Xxi, pp. 95-106.

- I937. The fauna of certain estuaries in West England and South Wales, with special reference to the Tanaidacea, Isopoda and Amphipoda. Fourn. Mar. Biol. Assoc., Vol. xxI, pp. 647-62.

Della Valle, A., I893. Gammarini del Golfo di Napoli. Fauna und Flora des Golfes von Neapel und der angrenzenden Meeres-Abschnitte, Monographie xx. Berlin.

GoodHart, C. B., I94I. The ecology of the Amphipoda in a small estuary in Hampshire. Fourn. Anim. Ecol., Vol. x, pp. 306-22.

HöFKeN, U., 1937. Statistische und experimentelle Untersuchungen über die Variabilität von Gammarus locusta (L.). Kieler Meeresforsch., Bd. II, pp. II6-48.

Howes, N. E., 1939. The ecology of a saline lagoon in south-east Essex. Fourn. Linn. Soc. Zool., Vol. XL, pp. 383-445.

MILNE, A., I940. The ecology of the Tamar Estuary. IV. The distribution of the fauna and flora on buoys. Fourn. Mar. Biol. Assoc., Vol. xxiv, pp. 69-87.

Percival, E., I929. A report on the fauna of the estuaries of the River Tamar and the River Lynher. Fourn. Mar. Biol. Assoc., Vol. xvi, pp. 8I-I08.

Poulsen, E. M., I932. On a collection of Gammarus from the waters south of Sealand. Vidensk. Medd. Naturh. Foren. Kjøb., Bd. 94, pp. I-I2.

ReID, D. M., I940. Three species of Amphipoda (Crustacea) new to Britain. Ann. Mag. Nat. Hist., Ser. xi, Vol. vi, pp. 335-7.

Sars, G. O., I895. An Account of the Crustacea of Norway. I. Amphipoda. Oslo.

SEgERSTRÅLE, S. G., I947. New observations on the distribution and morphology of the amphipod, Gammarus zaddachi Sexton, with notes on related species. fourn. Mar. Biol. Assoc., Vol. xxviI, pp. 219-44.

Serventy, D. L., I935. Observations on Gammarus zaddachi Sexton, an estuarine amphipod, and associated forms. Internat. Rev., Bd. xxxII, pp. 285-94.

Sexton, E. W., I9I2. Some brackish-water Amphipoda from the mouths of the Weser and the Elbe, and from the Baltic. Proc. Zool. Soc. London, I912, pp. 656-65.

— I913. On a collection of Gammarus from the Königsberg Museum. Schr. der Phys.-ökon. Ges. z. Königsberg i. Pr., Bd. LIv, pp. 90-4.

- 1942. The relation of Gammarus zaddachi Sexton to some other species of Gammarus occurring in fresh, estuarine and marine waters. Fourn. Mar. Biol. Assoc., Vol. xxv, pp. 575-606.

Sexton, E. W. \& Spooner, G. M., 1940. An account of Marinogammarus (Schellenberg) gen.nov. [Amphipoda] with a description of a new species M. pirloti. fourn. Mar. Biol. Assoc., Vol. xxiv, pp. 633-82.

Spooner, G. M. \& Moore, H. B., I940. The ecology of the Tamar Estuary. VI. An account of the macrofauna of the intertidal muds. Fourn. Mar. Biol. Assoc., Vol. xxIv, pp. 283-330.

Stebbing, T. R. R., I906. Amphipoda. I. Gammaridea. Das Tierreich, Lief. xxI, 806 pp. Berlin.

Stephensen, K., I940. The Amphipoda of N. Norway and Spitzbergen with adjacent waters. III. Tromsö Mus. Skr., Vol. III, pp. 279-362.

Tansley, A. G., 1939. The British Islands and their Vegetation. 970 pp. Cambridge. 


\section{APPENDIX}

\section{Tees Survey Collections: Samples Examined}

Section of
river

I

I

II

II

III

III

IV

IV

?

?

?

?

(XI-XIII)

XIII

?

?

?

?

?

\section{River Tees}

Label on tube

A. Yarm, I7. ix. 3I, shore

Revised naming

Remarks

G. pulex, 3

G. z. zaddachi, $9: 5$ ठิరో, 2 웅, 2 imm.

A. Shrimp trawl, 8. x. 3I

G. pulex, I very large ô

G. z. zaddachi, 5 ठิธิ์ 3 웅ํ, $\mathrm{I} 2 \mathrm{imm}$.

B. White House and Barwick, shore, I7. ix. 31

B. Shrimp trawl, 8. $x .3 I$

C. Above Preston Hall, shore, I7. ix. 31

G. $z$. zaddachi, large no. adults and imm.

G. z. zaddachi, $13: 5$ ठิరิ, 4 웅, 4 imm.

G. z. zaddachi, 34: 26 해어, 7 우우, I imm.

G. z. zaddachi, several ô ô, with I 우 and $2 \mathrm{imm}$.

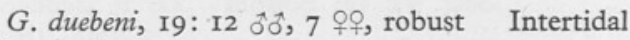
specimens

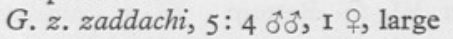

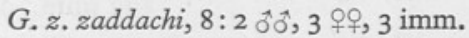

D. Shrimp trawl, 8. $x \cdot 31$

'Gammarus pulex... duebeni', from 8

'Gammarus duebeni'

Tow-netting, 9

Tow-netting, 7

Tow-netting, $7 \mathrm{~B}$

Tow-netting, Q II

Tow-netting, $\mathrm{T} 2 \mathrm{I} b$

Tow-netting, T 23

Tow-netting, $\mathrm{T} 25$

'Gammarus locusta'

'Gammarus marinus Leach’

I3. xii, I2. v. 30 'Gammarus pulex'

O.I. 26 . vi. 29 'Gammarus pulex'

B9. Io. ii. 30

'Gammarus pulex'

A6. 18. xi. 29

'Gammarus pulex'

A 56. 23. x. 29

'Gammarus pulex'
G. z. zaddachi, several large $\widehat{o}^{\hat{0}} \hat{~}$

G. z. zaddachi, 9: 6 ठํํ, 2 우우, I imm.

G. z. zaddachi, $\hat{\mathrm{o}}$

G. z. zaddachi, large $ᄋ$ with eggs

G. z. zaddachi, 6: 5 ô $\mathrm{o}^{,} \mathrm{I}$ 우 breeding

G. z. zaddachi, very large ठิ

G. locusta, young ô

G. locusta, 2 young ô 10,5 우우, several imm.

G. locusta, 6: 2 రิ

G. locusta, several

Gammarus locusta, I3

Marinogammarus marinus, 7

Amphithoë rubricata, I

Melita palmata, 2

G. pulex, several

G. pulex, two

G. pulex, 8

G. z. zaddachi, 3

G. z. zaddachi, 3 ô, I 우 


\begin{tabular}{cl}
$\begin{array}{c}\text { Section of } \\
\text { river } \\
\text { I }\end{array}$ & \multicolumn{1}{c}{ Label on tube } \\
II & Sect. I \\
III & Sect. II \\
IV & Sect. III \\
V & Sect. IV \\
(tidal zone) & Sect. V \\
VI & Sect. VI, tidal zone \\
& \\
& \\
$\#$ & Sect. VI, I3. Bottom \\
& Sect. VI, I4. Bottom \\
& Sect. VI, I5. Bottom \\
$\#$ & Sect. VI. Bottom \\
VIII & Sect. VIII. Tidal \\
& zone
\end{tabular}

IX Sect. IX. High-tide level

IX Sect. IX. Low-tide level

$\mathrm{x}$

$\mathrm{X}$

XI

XI

XI

\section{River Tay}

Revised naming

G. z. zaddachi: adults and imm., dwarf

G. z. zaddachi, 49: 37 ธิరె, 4 우우, 8 imm., dwarf

G. z. zaddachi: adults and imm., dwarf

G. z. zaddachi, several, dwarf

$G$. duebeni, a number of well-grown adults

G. duebeni, large sample, mainly well-grown adults

G. z. zaddachi, 6: 5 ธิ రิ, I imm. (one ot dwarf)

G. z. zaddachi, $7 \mathrm{imm}$.

G. z. zaddachi, II: 2 ธิరో, 2 우우, 7 imm., dwarf

G. $z$. zaddachi, several, maturing and imm., dwarf

G. z. zaddachi, dwarf, 우 and $4 \mathrm{imm}$.

G. duebeni, 67: 32 ธิธิ, 32 우우, 3 imm.; large

G. z. zaddachi, 42: 19 ठิరิ, 13 우웅 Io imm., very variable in size, some large, some dwarf

Marinogammarus marinus, 3: 2 है $\delta^{2}$, 'G. marinus' I 우

G. duebeni, a number of adults

M. marinus, I

M. marinus, a number

G. z. zaddachi, I $\widehat{\jmath}$

G. zaddachi, 'saline' form, 5 రิరో

G. duebeni, 39: 20 ठิరิ grown

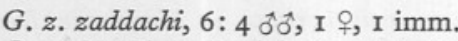

G. zaddachi, 'saline' form, 5: $4 \delta^{\widehat{t}} \mathrm{o}^{\hat{2}}$, I 우

Marinogammarus marinus, a number

Gammarus locusta, I ô

Marinogammarus marinus, 3

M. finmarchicus, I 우

Remarks.

Recorded as:

' $G$. zaddachi'

g

9

s

'G. duebeni'

9

,

s

,

99

9

,

9)

'G. duebeni'

' $G$. marinus'

' $G$. marinus'

'G. duebeni'

' $G$. locusta'

'G. duebeni'

'G. duebeni'

' $G$. locusta'

'G. marinus'

' $G$. locusta'

' $G$. marinus'

"

'G. marinus'

"s

' $G$. marinus'

s) 